\title{
Explorando las conexiones entre sistemas de medidas usados en prácticas cotidianas en el municipio de Baranoa
}

\author{
Exploring the connections between measurement systems \\ used in daily practices in the municipality of Baranoa
}

Camilo Andrés Rodríguez-Nieto

\begin{abstract}
RESUMEN
El propósito de esta investigación fue explorar las conexiones entre los sistemas de medidas usados en prácticas cotidianas del municipio de Baranoa. La investigación se enmarcó en la etnomatemática y en una metodología cualitativa-etnográfica, se aplicaron entrevistas semiestructuradas para la recolección de la información y un posterior análisis de datos, útil para reconocer los sistemas de medidas. Los resultados reportan siete sistemas de medidas y sus conexiones internas, externas y de significado desde una perspectiva etnomatemática, evidenciados en: la elaboración del bollo de yuca, cometas y cajones voladores, la ebanistería, la soldadura eléctrica, la agricultura y la ganadería. Además estos resultados son útiles para que el profesor de matemáticas haga conexiones cuando enseñe los sistemas de medidas a sus estudiantes, relacionando unidades de medidas convencionales y no convencionales.
\end{abstract}

Palabras clave: conexiones, sistemas de medidas, práctica cotidiana, artesano.

\begin{abstract}
The purpose of this research was to explore the connections between the measurement systems used on daily practices in the municipality of Baranoa. The research was framed in Ethnomathematics and a qualitative-ethnographic methodology, semi-structured interviews were applied to collect information and subsequently to perform data analysis, a useful process to recognize the measurement systems. The results report seven measurement systems and their internal, external, and meaning connections from an ethnomathematical perspective, evidenced in: the elaboration of the yucca bun, kites and flying boxes, cabinet making, electric welding, agriculture, and livestock. In addition, these results are useful for the Mathematics teacher to make connections while teaching measurement systems to their students, relating conventional and unconventional units of measurement.
\end{abstract}

Keywords: connections, measurement systems, daily practice, artisan. 


\section{INTRODUCCIÓN}

En los últimos años, varias investigaciones han enfatizado en explorar las matemáticas implícitas en las labores que las personas hacen en su vida cotidiana, donde se evidencian las actividades de medir, contar, diseñar, explicar, entre otras (Bishop, 1999; Gerdes, 2013; Rodríguez-Nieto, Mosquera y Aroca, 2019). Pero cada persona, según el lugar donde vive, incluyendo su entorno sociocultural, tiene un modo diferente de hacer sus oficios, de hablar, de bailar, de estudiar, tanto así que:

Cada pueblo tiene su matemática: su manera de contar, su manera de medir, su manera de estimar, su manera de orientarse en el espacio y en el tiempo, su manera de inventar formas, su manera de decorar sistemáticamente, su manera de explorar simetrías, su manera de clasificar... [Gerdes, 2013, p. 155].

Particularmente, la actividad de medir cumple un papel fundamental en el proceso de enseñanza y aprendizaje de las matemáticas y se encuentra implícita en distintas prácticas cotidianas. En este sentido, el NCTM (2000) sostiene que los procesos de medición son importantes dado que permiten el apropiamiento y la aplicación de otras matemáticas, por ejemplo, operaciones numéricas, nociones geométricas, manejo de conceptos estadísticos, destacándose las conexiones entre las matemáticas en sí mismas y entre las matemáticas y la vida cotidiana, incluyéndose estudios sociales, el arte, entre otros. También, desde la antigüedad el hombre tuvo la necesidad de medir y usaba partes de su cuerpo para establecer unidades de medida de longitud como la cuarta, el palmo, el pie, el paso, la braza, y utilizaba recipientes como unidades de medida de capacidad (Kula, 1980).

Pérez (1978) manifestó que los sistemas de medidas antiguos usados en España no han tenido especial atención, sin embargo no dejan de ser de interés en la actualidad, y su estudio reportó los sistemas de medidas de longitud, superficie, volumen y agrimensales empleados en Castilla, por ejemplo, la vara castellana en la ciudad de Burgos y sus relaciones: 1 vara de Burgos $=2$ medias varas castellanas $=3$ tercias o pies castellanos $=4$ cuartos o palmos castellanos $=6$ sexmas, jemes o medias tercias castellanas $=36$ pulgadas castellanas. Las equivalencias eran: 1 pie $=12$ pulgadas $=$ 16 dedos; 1 palmo $=9$ pulgadas $=12$ dedos.

Palerm y Chairez (2002) afirmaron que, antes de aceptar el sistema métrico decimal, en la Nueva España y en México se usaban las medidas de aguas (surcos, bueyes,

Camilo Andrés Rodríguez-Nieto. Universidad Autónoma de Guerrero, México. Es candidato a doctor en Ciencias con especialidad en Matemática Educativa de la UAGro, financiado por la Beca ConAcyт. Es Magister en Ciencias área Matemática Educativa y licenciado en Matemáticas por la Universidad del Atlántico (UA), Colombia. Es integrante del Grupo de Investigación Horizontes en Educación Matemática (GIHEM) de la UA. Ha publicado los artículos "Dos sistemas de medidas no convencionales en la pesca artesanal con cometa en Bocas de Cenizas" y "Estructuras semánticas de problemas aditivos de enunciado verbal en libros de texto mexicanos”. Correo electrónico: crodriguez@uagro.mx. ID: https://orcid.org/0000-0001-9922-4079. 
pajas, naranjas) con sus respectivas conversiones a litros por segundos y medidas de longitud (vara, pulgada, dedos) con sus equivalencias (figura 1). Además, en la antigüedad se mostraron características de las medidas de capacidad como medidas colmadas o a ras, usadas para la comercialización de granos (Castaño, 2015).

\begin{tabular}{|c|}
\hline Cuadro de equivalencias entre medidas antiguas de agua \\
\hline 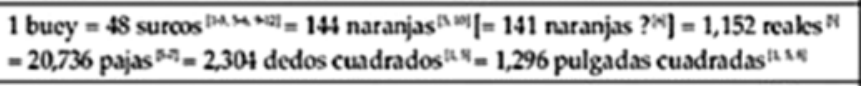 \\
\hline 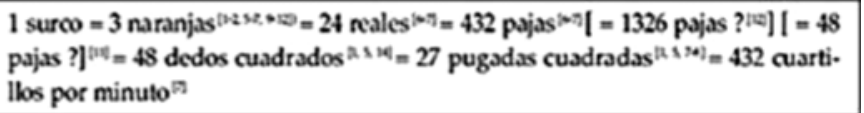 \\
\hline 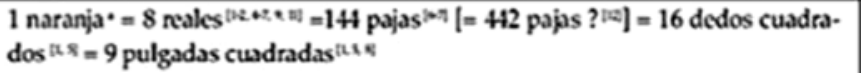 \\
\hline 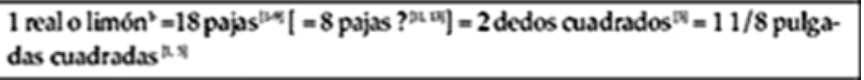 \\
\hline 4 reales = [18 pajas ? ?] \\
\hline 1 merced $^{\prime}=5$ pajas ${ }^{10 / 4}$ \\
\hline 9 pajas cuadradas=16 granos cuadrados=1 dedo cuadradon \\
\hline 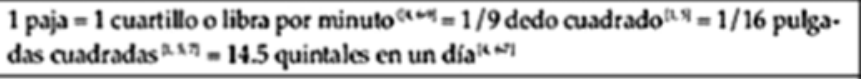 \\
\hline 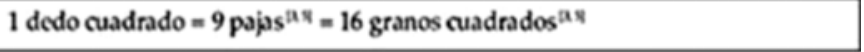 \\
\hline Equivalencias entre medidas antiguas (longitud) \\
\hline $\begin{array}{l}1 \text { vara }=2 \text { medias }=3 \text { teciass o pirs }=4 \text { cuartas o pulmos }=\text { seis sesmas }=\text { ocho odianus } \\
-36 \text { pulgadas }=48 \text { dolos }\end{array}$ \\
\hline 1 pulgada = 12 líneas \\
\hline 1 línea $=12$ puntos \\
\hline 1 dedo $=3$ pujits $=4$ granos \\
\hline
\end{tabular}

Figura 1. Equivalencias entre medidas antiguas de agua y de longitud. Fuente: Información tomada de Palerm y Chairez (2002).

Así como se han estudiado las medidas no convencionales desde un punto de vista antropológico, económico, metrológico y desde la agrimensura, también en la investigación en educación matemática se le atribuye importancia a los procesos de medición. Cronológicamente, en el apartado de antecedentes, se presentan algunos trabajos de etnomatemática sobre sistemas de medidas y otros estudios que consideran fundamental el establecimiento de conexiones.

\section{ANTECEDENTES}

Los trabajos sobre medidas antiguas y sistemas de medidas se han enfocado de la siguiente manera: Chieus (2009) reportó el uso de la braza para medir la longitud de redes de pesca. Rey y Aroca (2011) investigaron labores de albañiles, quienes hicieron estimación "al ojo" y midieron con el metro, el paso, la braza, la cuarta y la altura del ombligo, entre otras, para construir casas. Oliveira Júnior y Mendes dos Santos (2016) reconocieron el uso del palo o varilla y el palmar, la llave y el medio en la 
construcción de casas y ventanas. Se destacaron algunas equivalencias: 1 braza $=2$ $\mathrm{m} ; 1$ pie $=26 \mathrm{~cm} ; 1$ palmo $=22 \mathrm{~cm}$.

En el estudio de Ávila (2014) se identificaron mediciones de longitudes con el paso, la garrocha y la cuerda; el almud, la lata y el litro para medir granos; la tarea o el jornal para medir superficies y la jícara para medir capacidad. Muhtadi, Sukirwan, Warsito y Prahmana (2017) investigaron a la comunidad étnica de los sundaneses, encontrándose que las personas miden usando la siguiente terminología: Para la unidad de longitud usaban los términos sadepa, sapal, sahasta, sadim. En la unidad de área se identificaron palabras como sabata, sabektar, satumbak, sabau, y en relación con la unidad de volumen sakibik, sadam, sakojong, satelebug. En Rodríguez-Nieto, Morales-García, Muñoz y Navarro (2017) se reconocieron mediciones establecidas por comerciantes de un mercado, los cuales usan el litro, el cuartillo y la arpilla y las equivalencias entre ellas.

Trujillo, Miranda y De la Hoz (2018) reportaron unidades de medidas empleadas en la comunidad Arhuaca. Utilizaban la braza y la vara grande en la siembra del café y construcción de viviendas; la cuarta, el jeme y el codo en la siembra de hortalizas, el paso y el pie en la elaboración de mochilas. Supiyati, Hanum y Jailani (2019) exploraron los elementos culturales en las arquitecturas y construcciones Sasak, en dichas construcciones se usaban medidas antropométricas como: seperunjung, sedepa (braza), sejengkak (jeme), sekepal, karang ulu (estatura de la persona) y senyari (ancho del dedo índice), e identificaron conceptos como ángulo, triángulo y cilindro.

Otros trabajos han reportado mediciones en la pesca con cometas donde prevalece el uso de la cuarta, jeme, dedos y la braza (Mosquera, Rodríguez-Nieto y Suárez, 2015; Rodríguez-Nieto, Mosquera y Aroca, 2019). Cabe destacar que en Mosquera, Rodríguez-Nieto y Suárez (2015), con base en los resultados del estudio etnográfico, se diseñó y se implementó una situación didáctica con base en las medidas encontradas (no convencionales), con estudiantes de secundaria, donde se obtuvo que, después de la aplicación de un cuestionario, los estudiantes reconocían otras formas de medir. García-García y Bernandino-Silverio (2019) exploraron los conocimientos geométricos implícitos en el uso y la elaboración del güilile, donde encontraron nociones geométricas: circunferencia, parábola, intersección de rectas y el uso de la cuarta. Aravena-Pacheco, Loncomilla-Gallardo y Pizarro-Cisternas (2020) y Castro-Inostroza, Rodríguez-Nieto, Aravena-Pacheco, Loncomilla-Gallardo y Pizarro-Cisternas (2020) identificaron nociones matemáticas en la labor de un mueblista como la medición con la tolerancia, el centímetro, el metro, la pulgada y mediciones de ángulos. En Rodríguez-Nieto, Aroca y Rodríguez-Vásquez (2019) se reconocieron los procesos de medición de un comerciante de bollos de yuca, quien emplea unidades de medidas no convencionales y convencionales como la carga, el bulto, el tercio, el lao, balde, tanque, la braza y el metro. 
Las investigaciones revisadas muestran el potencial de los procesos de medición en las prácticas cotidianas y el impacto que causan en las clases de matemáticas (Mosquera, Rodríguez-Nieto y Suárez, 2015). Sin embargo, en la mayoría de las investigaciones solo se han reportado medidas que emergen en una sola práctica cotidiana, perteneciente a una región donde también se desarrollan otros tipos de prácticas cotidianas que deberían ser exploradas y articuladas, es decir, es fundamental reconocer el potencial de las conexiones entre sistemas de medidas y cómo podrían favorecer a la enseñanza y aprendizaje de las matemáticas. Por lo tanto, el objetivo de esta investigación fue explorar las conexiones entre los sistemas de medidas usados en prácticas cotidianas desarrolladas en el municipio de Baranoa.

Por otra parte, en educación matemática hay una tendencia en la investigación sobre el tema de las conexiones matemáticas (e.g., García-García y Dolores-Flores, 2020; Rodríguez-Nieto, Rodríguez-Vásquez y Font, 2020) y estas investigaciones se refieren a que un sujeto que haga conexiones entre ideas matemáticas, conceptos, significados, procedimientos, entre otros, puede lograr comprensión matemática (García-García, 2019). Asimismo, hacer procesos de medición, conteos, diseños en diferentes prácticas, podría tener más amplitud para aplicar las matemáticas y conectarlas con la vida real (NCTM, 2000).

Algunas investigaciones que no están enmarcadas en la etnomatemática han centrado su atención en las conexiones o vínculos entre la matemática y el entorno de los estudiantes, tal como se muestra en Alsina (2012), donde se identificó que las conexiones giraron en torno a que los profesores matematizaron un contexto particular (el patio) con el fin de concretar contenidos matemáticos. Asimismo consideró la resolución de problemas; el razonamiento lógico; la numeración, haciendo procesos de conteo; la geometría, reconociendo las figuras de los objetos encontrados en el patio; la medida (uso de instrumentos para medir objetos de una plaza); las representaciones (gráficas, dibujos y signos), y en cuanto a las conexiones, se trabajaron relaciones entre contenidos matemáticos, con otras áreas curriculares y con el entorno. Otros trabajos han usado las conexiones intramatemáticas y extramatemáticas (e.g., Businskas, 2008; Dolores-Flores y García-García, 2017), pero no las relacionan con fenómenos cotidianos o de tipo etnomatemático.

En la literatura sobre investigaciones basadas en la etnomatemática se identificó que algunas puntualizan en el rol importante que tienen las conexiones, por ejemplo, Madusise (2015) afirma que "la educación matemática debe estar conectada con la cultura de los estudiantes” (p. 11), pero identificó que en los procesos de enseñanza y aprendizaje poco se enfatiza en establecer conexiones entre las matemáticas y la cultura, y las pocas conexiones que hacen son superficiales. Asimismo, este estudio exploró el conocimiento indígena, para que los profesores llevaran ese conocimiento al aula de clases a través de actividades contextualizadas, de las cuales, después de haber sido implementadas, algunos profesores reconocieron que es importante co- 
nectar las matemáticas con la cultura, porque facilita a los estudiantes el aprendizaje por sus propios medios utilizando su contexto (Madusise, 2015). De igual manera, Rosa y Orey (2018) reconocen que la etnomatemática posibilita la conexión entre las matemáticas y las prácticas culturales que se desarrollan de manera local.

En el estudio de Trujillo, Miranda y De la Hoz (2018) se identificaron relaciones entre los sistemas de medidas usados en la comunidad Arhuaca, quienes usan medidas autóctonas de longitud en diferentes contextos, encontrándose puntos en común, por ejemplo, la cuarta y el jeme se usan en la elaboración de mochilas y siembra de hortalizas. De manera similar sucede con la unidad de medida braza, usada en la construcción de casas y siembra de hortalizas. Por su parte, García-García y Bernandino-Silverio (2019) sugieren que es importante incluir la elaboración del güilile en los procesos de enseñanza y aprendizaje de la matemática, dado que permitiría el establecimiento de conexiones entre los conocimientos matemáticos desarrollados en la escuela y los construidos por las personas que elaboran el artefacto en una práctica cotidiana. Además manifiestan que se podrían promover conexiones de carácter intramatemático entre conceptos geométricos y conexiones de tipo extramatemático con otras disciplinas. Sin embargo, en estas investigaciones basadas en la etnomatemática le dan importancia a las conexiones, pero no se profundiza en alguna clasificación de las conexiones que emerjan en la práctica cotidiana estudiada.

\section{Marco CONCEPTUAL}

\section{Medir, medición y unidad de medida}

La actividad de medir se evidencia en el uso de materiales concretos, de hecho, un atributo medible es una característica de los objetos que pueden cuantificarse (NCTM, 2000). Para la Real Academia de la Lengua Española (RAE, 2018), "medir” es comparar una cantidad (A) con su respectiva unidad de medida (B), con el objetivo de averiguar cuántas veces B está contenida en A. De igual manera, en Secretaria da Educação (2012) se asume que "medir es comparar una cantidad con un estándar y expresar el resultado de la comparación por medio de un número" (p. 43).

Desde el NCTM (2000), "la medición es la asignación de un valor numérico a un atributo de un objeto... en niveles más sofisticados, la medición implica asignar un número a una característica de una situación” (p. 44). También se considera que la unidad de medida es la cantidad usada como elemento de comparación reiterada (Godino, Batanero y Roa, 2002). Estos elementos conceptuales son útiles para interpretar los resultados.

\section{E1 programa etnomatemática}

Varios autores han definido la etnomatemática, entre ellos Barton (1996), quien sostiene que es "un intento de describir y comprender las formas en que las ideas que 
el etnomatemático llama matemáticas son entendidas, articuladas y utilizadas por otras personas que no comparten la misma concepción 'matemática”' (p. 215). Pero en la mayoría de las investigaciones enmarcadas en este campo de investigación se ha usado la definición de D’Ambrosio (2001), que afirma que la etnomatemática “es la matemática practicada por grupos culturales, tales como comunidades urbanas o rurales, grupos de trabajadores, clases profesionales, niños de cierta edad, sociedades indígenas y otros grupos que se identifican por objetivos y tradiciones comunes a los grupos" (p. 9).

Etimológicamente, la etnomatemática se denomina como "el conjunto de modos, estilos, artes y técnicas (technés o ticas) para explicar, aprender, conocer, lidiar en/ con (matemâ) los ambientes naturales, sociales, culturales e imaginarios (etnos) de una cultura” (D’Ambrosio, 2014, p. 103), es decir, para D’Ambrosio la etnomatemática son las ticas de matemá en un determinado etno. Sin embargo, en las definiciones anteriores no se especifican otras actividades donde se evidencia la etnomatemática. Por tal motivo, Aroca (2016) presentó otra perspectiva ampliada de etnomatemática enfatizando en que:

No solo es lo sociocultural, también es lo histórico, lo político, lo ético, su relación con la educación, la formación, la pedagogía, la didáctica, lo religioso, lo económico, lo psicológico, lo lingüístico que median en la enseñanza y aprendizaje de las matemáticas, y no a todas estas dimensiones las podemos interpretar mediante las tics de mathema en una etno [p. 192].

Aunque la etnomatemática desde sus inicios haya tenido sus fundamentos conceptuales enmarcados en la antropología, la filosofía de las matemáticas y la historia (D’Ambrosio y Knijnik, 2020), en esta investigación se considera que las definiciones de etnomatemática propuestas por D’Ambrosio (2001, 2014) y Aroca (2016) articuladas, son el soporte teórico que permite estudiar y analizar la matemática usada por grupos culturales en diferentes prácticas cotidianas, y también en la mayoría de las investigaciones se considera la etnografía para la exploración y análisis de prácticas cotidianas. Además, el programa etnomatemática "enfatiza en la importancia de las comunidades en relación con el ambiente escolar, debido a que conecta la matemática con las prácticas culturales desarrolladas y utilizadas localmente" (Rosa y Orey, 2018, p. 72).

\section{Conexión}

Esta investigación se enfoca en la exploración de los sistemas de medidas pero también se considera a las conexiones, entendidas como "una relación verdadera entre dos ideas matemáticas A y B” (Businskas, 2008, p. 18). Estudios sobre etnomatemática han puntualizado en que las conexiones son importantes para relacionar la matemática con el entorno sociocultural de un sujeto (Madusise, 2015; Rosa y Orey, 2018; García-García y Bernandino-Silverio, 2019), pero no reportan alguna caracterización 
de las conexiones en sus resultados o que hayan usado como fundamento teórico. Otras investigaciones han usado y propuesto categorías de conexiones intramatemáticas (e.g., significado, representaciones diferentes, procedimental) (Businskas, 2008; García-García, 2019; García-García y Dolores-Flores, 2020; Rodríguez-Nieto, Rodríguez-Vásquez y Font, 2020) y extramatemáticas (modelado) (Dolores-Flores y García-García, 2017), pero no las asocian a contextos etnomatemáticos, sino con conceptos del cálculo como la derivada y la integral. Por tanto, en esta investigación no se considera una categorización de conexiones a priori para analizar los datos sobre las prácticas cotidianas, tampoco se descarta la posibilidad de usar algunas categorías ya existentes, dado el caso que se necesite si emerge una nueva categorización de conexiones desde un punto de vista etnomatemático y los sistemas de medidas.

\section{Metodología}

Bajo una metodología cualitativa exploratoria, de enfoque etnográfico ${ }^{1}$ (Hernández, Fernández y Baptista, 2014), se realizó esta investigación considerando tres etapas: 1) se hizo el trabajo etnográfico permitiendo el acercamiento con los artesanos (familiarización ${ }^{2}$ ); 2) se realizaron entrevistas semiestructuradas; 3) se analizaron los datos, haciendo descripciones de las prácticas cotidianas, y simultáneamente se reportaron los sistemas de medidas.

En realidad la metodología empleada en este estudio, métodos de recolección y análisis de datos tiene coherencia con lo sugerido por D’Ambrosio (2014) cuando manifestó que una metodología para trabajar en etnomatemática es:

La capacidad de observación y análisis. Una vertiente de Etnomatemática es describir y comprender las prácticas de las poblaciones y de diferentes grupos, no necesariamente indígenas o mestizos o habitantes de la periferia. Es una actividad de observación de lo que se hace en algunas situaciones, es un reconocimiento de acciones ad hoc [p. 105].

\section{Participantes y contexto}

Los participantes $(\mathrm{P})$ del estudio fueron ocho artesanos voluntarios que desempeñan sus prácticas cotidianas en el municipio de Baranoa ${ }^{3}$ (tabla 1). En el análisis y resultados, el entrevistador (autor de la investigación) se denominó E.

1 Describir y comprender el estilo de vida de las personas, por medio de la observación participante, dando la oportunidad de ver e interactuar con la finalidad de captar el significado de las acciones y los sucesos que ocurren en una práctica cultural (Ameigeiras, 2006).

2 Comprender la forma de cómo el grupo o persona experimenta, define y significa su realidad personal y cultural (Sandoval, 2002).

3 Municipio del departamento del Atlántico, Colombia. Sus habitantes hacen labores artesanales, las cuales han emergido y evolucionado por la conservación de la cultura indígena (Mokaná). Tiene tres corregimientos (Campeche, Pital y Sibarco). Es denominado el "Corazón alegre del Atlántico" por su carnaval, la loa, la banda de música departamental y sus festivales de la ciruela, del pastel y del guandú con bollo de yuca. 
Tabla 1. Participantes de la investigación.

\begin{tabular}{ccccc} 
Participante $(\mathrm{P})$ & Nombre & Edad (años) & Práctica cotidiana & Experiencia (años) \\
\hline P1 & Jesús & 63 & Elaboración de bollos & 40 \\
\hline P2 & Wilson & 62 & Ebanistería & 30 \\
\hline P3 & José & 45 & Elaboración de cometa & 32 \\
\hline P4 & Sigifredo & 63 & Elaboración del cajón volador & 45 \\
\hline P5 & Fauto & 59 & Soldadura & 35 \\
\hline P6 & Carlos & 23 & Soldadura & 8 \\
\hline P7 & Arturo & 70 & Agricultura & 55 \\
\hline P8 & Ramiro & 63 & Agricultura y ganadería & 48 \\
\hline
\end{tabular}

Fuente: Elaboración del autor con la información del trabajo de campo.

\section{Recolección de datos}

Por medio de la entrevista semiestructurada (Longhurst, 2010) se recolectaron los datos, dado que se hizo un intercambio verbal entre el investigador y los participantes. Durante la entrevista, el investigador preguntaba: “CCómo realiza un mueble?”, “¿Qué elementos consideras para elaborar una cometa?”. Posteriormente, en medio del diálogo, el entrevistado mencionaba aspectos clave de su práctica y de inmediato se le hacía una pregunta para profundizar en dicho aspecto, es decir, las preguntas emergían de manera natural en el diálogo.

Desde la perspectiva de D’Ambrosio (2014) se procedió en esta investigación, dado que la etnomatemática enfatiza en la observación de prácticas de grupos culturales a comprender la simbiosis entre el hacer y saber, es decir, analizar y profundizar en lo que hacen las personas.

\section{Análisis de datos}

Para analizar los datos se usaron algunas fases del método de análisis propuesto por Hernández, Fernández y Baptista (2014), con adaptaciones para hacer el análisis de prácticas cotidianas: 1) se transcribieron las entrevistas y se leyeron para lograr una familiarización con los datos; 2) se identificaron frases o palabras clave, códigos (en las transcripciones) que implícitamente sugieren una unidad de medida (convencional o no convencional); 3) se hizo un reporte de todas las unidades de medidas que conforman el sistema de medida de cada práctica cotidiana, considerando extractos de audio y fotografías; 4) se agruparon las unidades de medidas teniendo en cuenta las conversiones y equivalencias, de las cuales se infirieron las conexiones; 5) se presentan las conexiones entre aspectos similares (unidades de medida) de cada sistema de medida, con el fin de relacionar prácticas desarrolladas de manera aislada en un mismo entorno sociocultural (en este caso en Baranoa). 


\section{Ejemplo de análisis de datos}

En la transcripción de la entrevista realizada a P3 se identificó la cuarta como unidad de medida no convencional.

P3. Depende de qué medidas quiere uno las varillas, esta la vamos a hacer de cinco cuartas, la cuarta es...

E. ¿Qué es la cuarta?

P3. La medida que uno hace en la cometa, "del dedo pulgar al meñique" abierta la mano.

En el apartado de resultados se describen características de los participantes, sus estilos de vida, otros empleos e información relevante de un estudio etnográfico.

\section{Resultados}

Los participantes de este estudio elaboran artefactos, cometas, bollos, muebles, cultivos, en los cuales se identificaron nociones matemáticas, como la actividad de medir. A continuación se describen las prácticas cotidianas y enseguida se mencionan los procesos de medición y sistemas de medidas.

\section{Sistema de medida en elaboración del bollo de yuca}

El participante P1 es oriundo del corregimiento de Sibarco, es uno de los comerciantes de bollo de yuca más reconocido, por la calidad de su producto. Para la elaboración de los bollos se evidenciaron doce fases (ver con más detalles en Rodríguez-Nieto, Aroca y Rodríguez-Vásquez, 2019). La primera fase es arrancar la yuca (Manihot esculenta) y empacarla en sacos de 120 libras cada uno. Segundo, se transporta la yuca en un burro, colocándole una carga de yuca equivalente a dos sacos de yuca (figura 2).

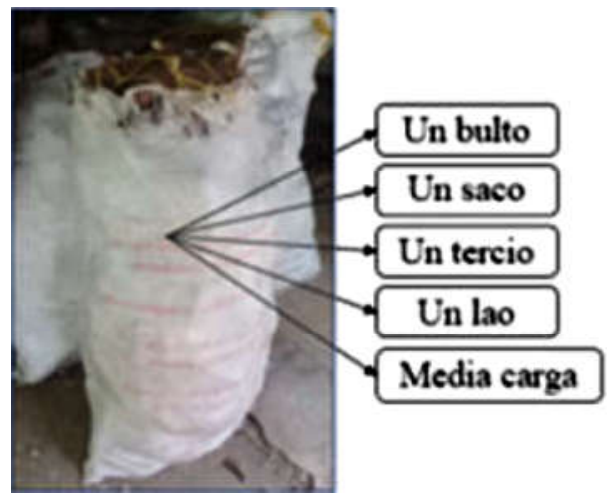

Figura 2. Unidades de medidas identificadas en la fase de arrancar y empacar la yuca. Fuente: Elaboración del autor con información del trabajo de campo.

En la tercera fase, se pela la yuca (quitar la cáscara) empleándose media hora por cada bulto de yuca. La cuarta fase es el lavado de la yuca, importante para la higiene del producto. La quinta fase concierne a la rallada de la yuca para conseguir la masa 
(harina), en la cual se emplea la ralladora eléctrica durante diez minutos por cada saco de yuca. La sexta fase consiste en exprimir la masa mojada, sacarle el líquido (almidón ${ }^{4}$ ).

La séptima fase se refiere a la limpieza de la masa, con el propósito de quitarle los palitos o residuos de la yuca, dejándola en óptimas condiciones para el armazón del bollo. La octava fase es el peloteo de la masa, es decir, amasar y hacer la masa en forma de elipsoide relleno (bollo), macizo, no hueco. La novena fase corresponde a la envoltura de la masa con la hoja de maíz donde P1 usa culeros ${ }^{5}$ que miden cinco centímetros de ancho (figura 3a). La décima fase hace alusión al amarre de la masa, es decir, se toma la masa envuelta y se amarra con una pita (hilo) que mide una brazada (braza) que para P1 equivale a dos metros (figura 3b) y es igual a la altura de la persona (figura 3c). Según P1, la mitad de la pita mide un metro y es equivalente a la medida del suelo hasta el ombligo (figura 3d), y el largo del bollo mide un jeme (figura 3e).

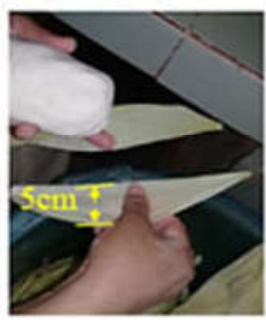

Figura 3a. Medida del ancho del culero.

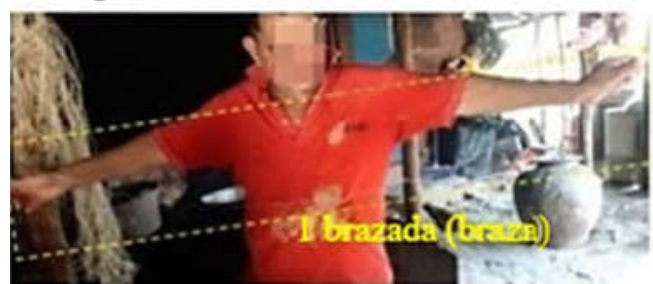

Figura 3b. La pita mide una braza.

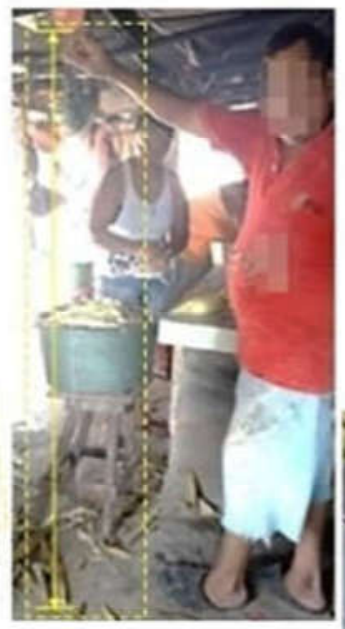

Figura $3 c .1$ brazada $=$ altura de la persona.

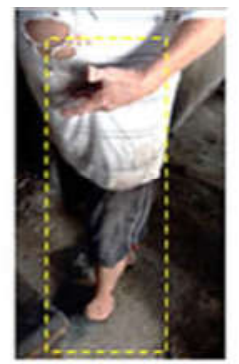

Figura 3d. Un metro $=$ altura del ombligo.

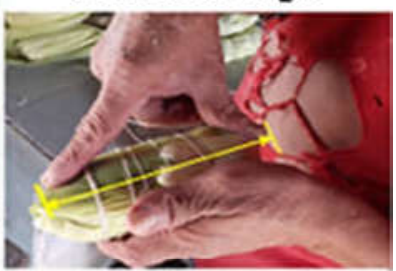

Figura $3 \mathrm{e}$. La medida del largo del bollo es un jeme.

Figura 3. Medidas usadas por P1 en las fases: envolver y amarrar la masa. Fuente: Elaboración del autor con información del trabajo de campo.

Por último, se cocinan los bollos en un tanque al que le caben doscientos bollos y se emplean siete baldes de agua (15 litros cada uno), equivalentes a medio tanque (figura 4a). Asimismo, P1 usa la leña para la candela, comercializada por carga (1 carga $=$ dos laos) (figura 4b).

4 Derivado de la yuca el cual funciona como alimento o pegamento usado en trabajos de papelería.

5 Son dos pedazos de la hoja del maíz, usada para cubrir la masa y evitar que se derrame. 


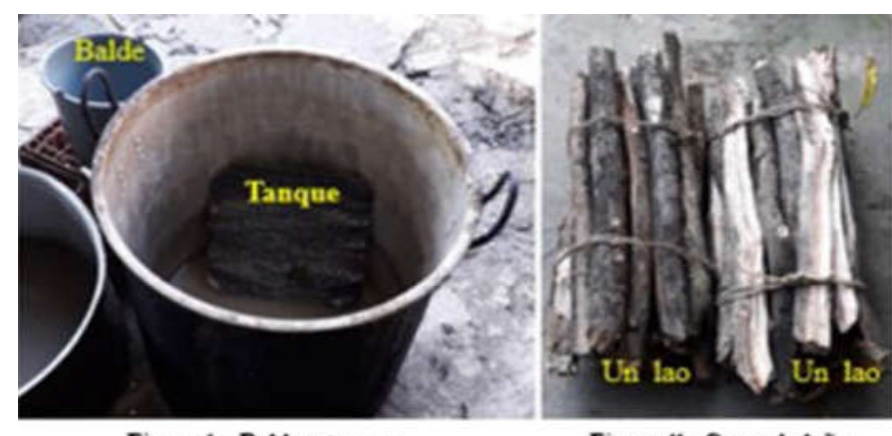

Figura 42. Balde y tanque

Figura tb. Carga de letia

Figura 4. Medidas evidenciadas en elementos clave de la fase: cocinar los bollos y equivalencias entre carga-lao; tanque-balde. Fuente: Elaboración del autor con información del trabajo de campo.

En las fases de elaboración del bollo de yuca se han evidenciado unidades de medidas convencionales (libra, centímetro, metro, litro) y no convencionales (bulto, saco, lao, carga, tercio, jeme, braza, altura de la persona, altura del ombligo). Estas unidades de medida conforman el sistema de medida usado por P1 en la elaboración del bollo de yuca. Además se identificaron equivalencias, las cuales llevaron a establecer conexiones internas entre unidades de medidas (tabla 2). En este sentido, las conexiones internas son las relaciones que hace un sujeto entre unidades de medidas (convencional o no convencional) de un mismo sistema de medida usado en una práctica cotidiana, considerando equivalencias y conversiones.

Tabla 2. Conexiones entre unidades de medidas establecidas por P1.

Equivalencias y conversiones

1 saco de yuca $=120$ libras de yuca

1 balde de agua $=15$ litros agua

7 baldes de agua $=105$ litros de agua

$1 / 2$ tanque de agua $=7$ baldes de agua

\section{Conexiones internas}

Conexión entre una unidad de medida no convencional y otra convencional

Conexión entre unidades medidas no convencionales

1 braza $=$ altura de la persona

$1 / 2$ pita $=$ altura del ombligo

$1 / 2$ pita $=1 / 2$ braza

Fuente: Elaboración del autor con información del trabajo de campo.

Las equivalencias entre unidades de medidas permiten observar que P1 realiza conexiones entre dos sistemas de medidas (no convencional y convencional).

\section{Sistema de medida en la ebanistería}

P2 hace producciones innovadoras como closets, puertas, ventanas, entre otras, y trabaja la albañilería. En la elaboración de un closet se observó que P2 usa medidas estandarizadas como el centímetro, el metro, la pulgada, como se evidencia en la figura 
5a. También mencionó que en la elaboración del closet emplea la escuadra para que todo quede a noventa grados (figura 5b); P1 usa la escuadra para medir y verificar el corte o ensamble de la espiga en el escople.

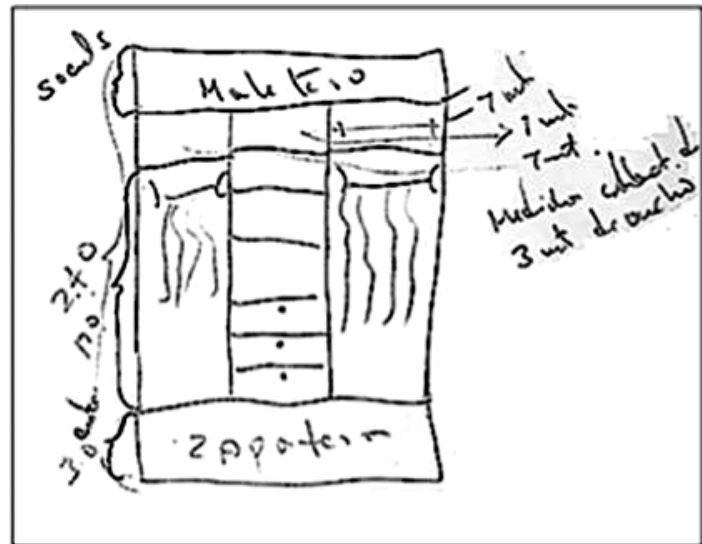

Figura 5a. Uso de medidas estandarizadas (centimetro y metro)

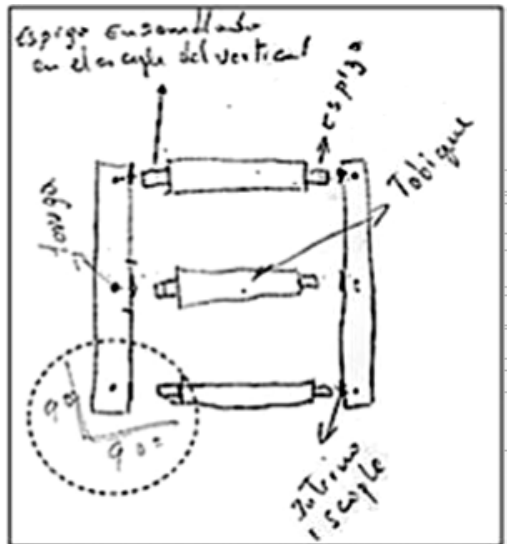

Figura 5b. Medición de ángulos con escuadra.

Figura 5. Medidas estandarizadas usadas por P2 en la elaboración de closet y puertas. Fuente: Elaboración del autor con información del trabajo de campo.

Además, en la elaboración de las puertas P2 usa equivalencias entre unidades de medidas convencionales y no convencionales, como la "altura del ombligo", equivalente a un metro (figura 6).

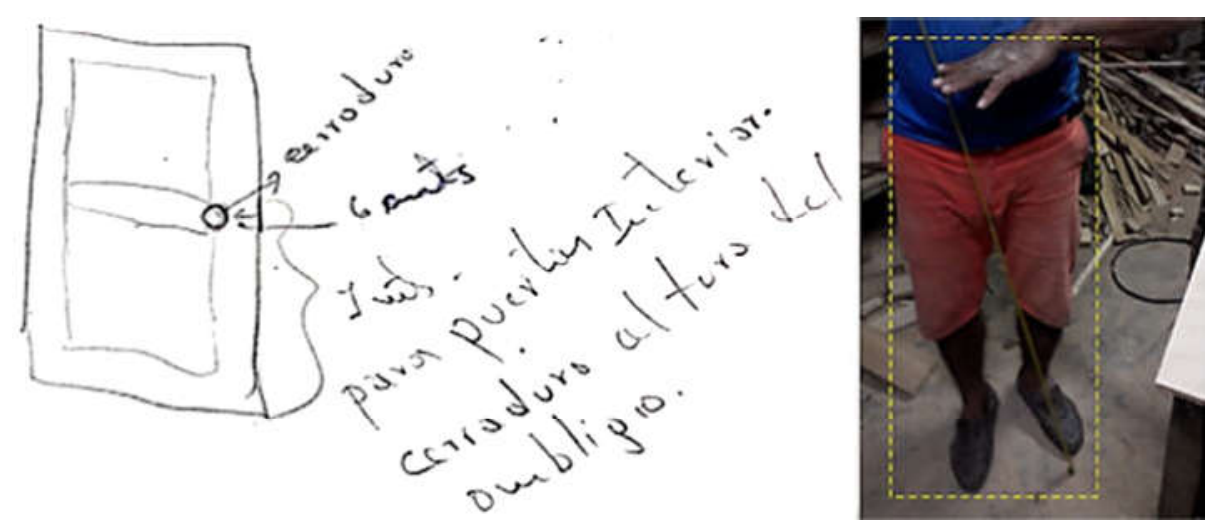

Figura 6. Unidad de medida no convencional, la "altura del ombligo".

Fuente: Elaboración del autor con información del trabajo de campo.

En el siguiente extracto de entrevista se da evidencia del uso de la unidad de medida "la altura del ombligo", fundamental para la instalación de cerraduras de puertas interiores de casa.

P2. Para la instalación de la cerradura, lo normal es que la cerradura quede a un metro.

E. ¿De dónde a dónde?

P2. Un metro... desde el piso hasta la mitad de la puerta, generalmente uno la pone a la "altura del ombligo", que tiene un metro, es una medida artesanal. 
Asimismo, para P2 la cuarta es una unidad de medida recursiva, dando a entender que si en algún momento lo buscan para un trabajo y no tiene un metro, puede usar la cuarta para medir y dar un precio aproximado del mueble (figura 7). Además estableció equivalencias cuando midió su cuarta, la cual es igual a 20 centímetros, equivalente a 8 pulgadas. Afirmó que cinco cuartas equivalen a un metro (figura 7).
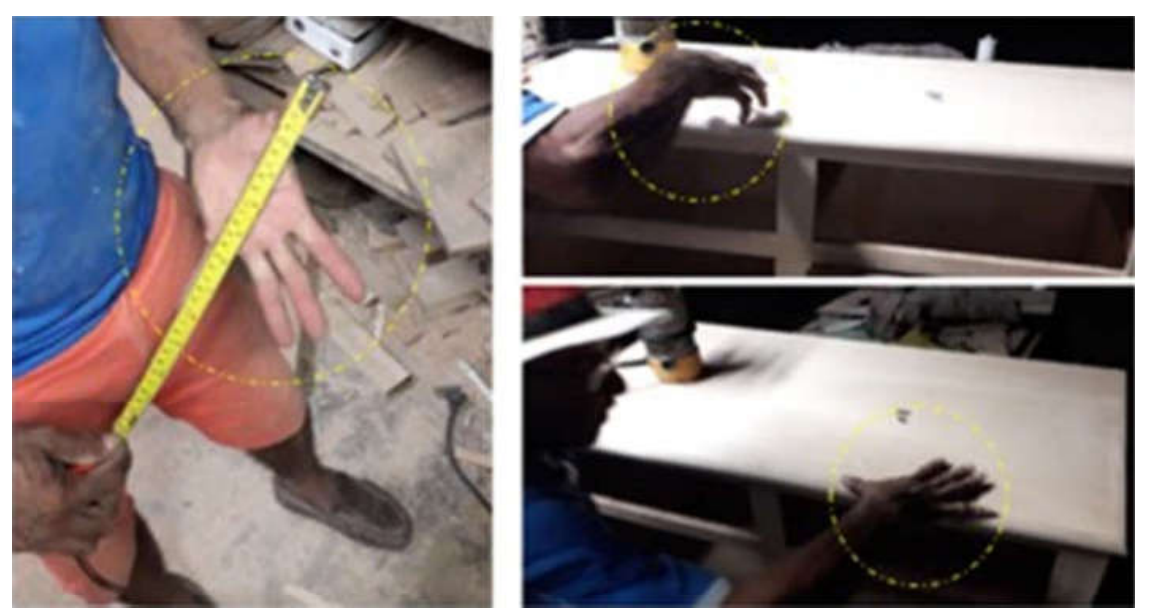

Figura 7. Uso de la cuarta como unidad de medida recursiva.

Fuente: Elaboración del autor con información del trabajo de campo.

En el siguiente extracto de entrevista se amplía la explicación de P2 acerca del uso de la cuarta en la labor de un ebanista.

P2. Una cuarta son veinte centímetros... ocho pulgadas.

E. ¿Por qué la cuarta?

P2. En caso extremo que no tengas algo y vayas a medir esto [madera], por decir, "hey, hazme un mueble de tantas cuartas", una, dos... cinco cuartas, es un metro completico.

Se evidenciaron unidades de medidas usadas por un ebanista cuando elabora puertas y closets, las cuales constituyen su sistema de medidas (ver tabla 3), y dejó entrever las conexiones entre las equivalencias y conversiones.

Tabla 3. Conexiones entre unidades de medidas usadas por el ebanista.

Equivalencias y conversiones

1 metro = altura del ombligo

1 metro $=5$ cuartas

1 cuarta $=20$ centímetros

1 cuarta $=8$ pulgadas

\begin{tabular}{cc}
\hline Altura del ombligo $=5$ cuartas & Conexión entre unidades de medida no convencionales \\
\hline $\begin{array}{c}\text { Altura del ombligo }=100 \text { centímetros } \\
\text { Altura del ombligo }=40 \text { pulgadas }\end{array}$ & Conexión entre una unidad de medida no convencional y otra convencional \\
\hline 20 centímetro $=1$ pulgada & Conexión entre unidades de medidas convencionales \\
1 metro $\cong 40$ pulgadas & \\
\hline
\end{tabular}




\section{Sistema de medida en la elaboración de cometas}

El participante P3 pertenece a la etnia Mokaná. Se ha desempeñado tocando instrumentos musicales de percusión (tambores) y de viento como la trompeta, y hace comentas en diciembre. P3 enfatizó que para hacer una cometa se necesitan cañas de bambú, pita, cuchillo, martillo, y para forrar usa plástico o papel de cometa. Además se tienen que seguir siete fases: primero se empareja la caña con una cinta y una segueta, teniendo en cuenta la medida a la que se desee hacer la cometa (tamaño; ver el siguiente extracto de entrevista y la figura 8a).

P3. Cuando haces la cometa, vas midiendo la cantidad de pita.

E. ¿Cuáles medidas?

P3. ¿De la pita?

E. Sí, cuando tú dices "midiendo", ¿a qué te refieres?

P3. Comenzamos emparejando primero la caña, puede ser con un metro para cortarla.

Segundo, se sacan las cinco cañas (varillas) que conforman una cometa (dos largas o parales), una varilla central, la varilla del arco y la varilla que sostiene al arco (ver extracto de audio y figura $8 b)$.

P3. Esta la vamos a hacer de cinco cuartas, la cuarta es...

E. ¿Qué es la cuarta?

P3. La medida que uno hace en la cometa, "del dedo pulgar al meñique" abierta la mano. Comenzamos a sacar las varillas... primero medimos la caña para saber si dan las cinco cuartas, si queremos hacer la cometa de cinco, cuatro cuartas, la altura de la cometa.

En la tercera fase las varillas se redondean y se verifican según su medida. Las dos varillas largas deben tener igual medida, la varilla central debe tener menor medida que las largas, P3 dijo, "para que la cometa no quede ni muy ancha ni muy delgada"; la varilla que sostiene el arco generalmente se sitúa desde el centro hasta el arco y la varilla del arco se ubica en la parte superior de la cometa y es la de menor medida (figura 8c y el siguiente extracto de entrevista).

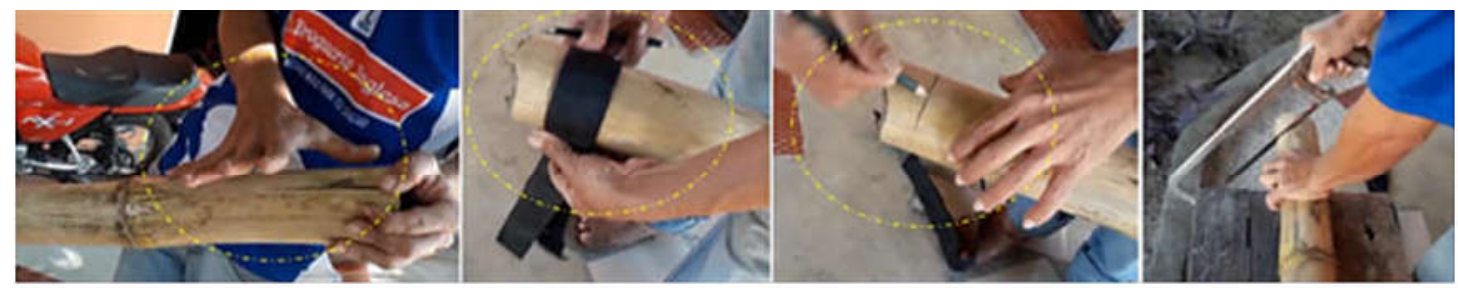

Figura 8a Medir y emparejar la cala

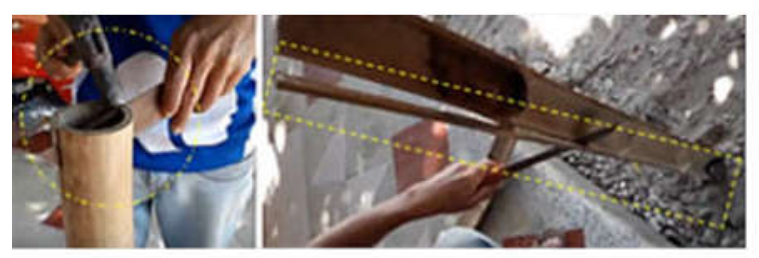

Figura 8b. Sacar las cinco varillas de catla.

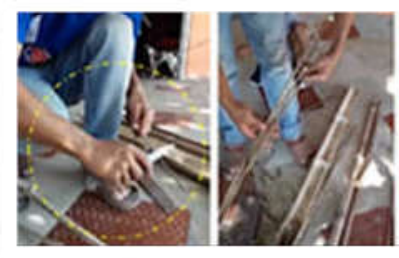

Figura 8c. Redondear y verificar las varillas.

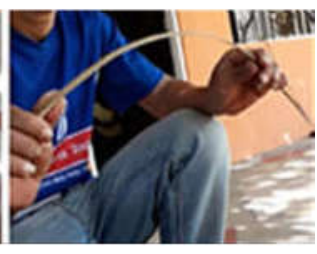

Figura 8. Proceso de medición y corte de la caña para sacar las varillas de la cometa. Fuente: Elaboración del autor con información del trabajo de campo. 
P3. La cometa está elaborada por cinco varillas... hay unas que son de tres varillas, porque esas no llevan arco, esas nada más llevan los dos parales y la varilla del centro.

E. ¿Qué papel juega el arco en la cometa?

P3. Por lo menos cuando uno le va a hacer el ico, ${ }^{6}$ su altura.

En la cuarta fase, se amarran las varillas largas de la cometa teniendo en cuenta que el nudo quede ubicado en la mitad de ellas (figura 9a). Además mencionó que después de haber cortado una varilla larga, esta le sirve para medir la otra y quedan de igual medida, es decir, usa un patrón de medida (ver el siguiente extracto de entrevista). En este proceso P3 usa medidas no convencionales como medir con la pita, la cuarta, el jeme ${ }^{7}$ y los dedos (figura 9b).

P3. Tomamos la otra varilla y la medimos.

E. ¿Qué haces?

P3. Estoy midiendo la otra varilla para que queden iguales.

E. ¿Ya no utilizas las cuartas?

P. No, porque en una varilla tengo la medida de las cuartas, entonces coloco la otra varilla en la misma medida.
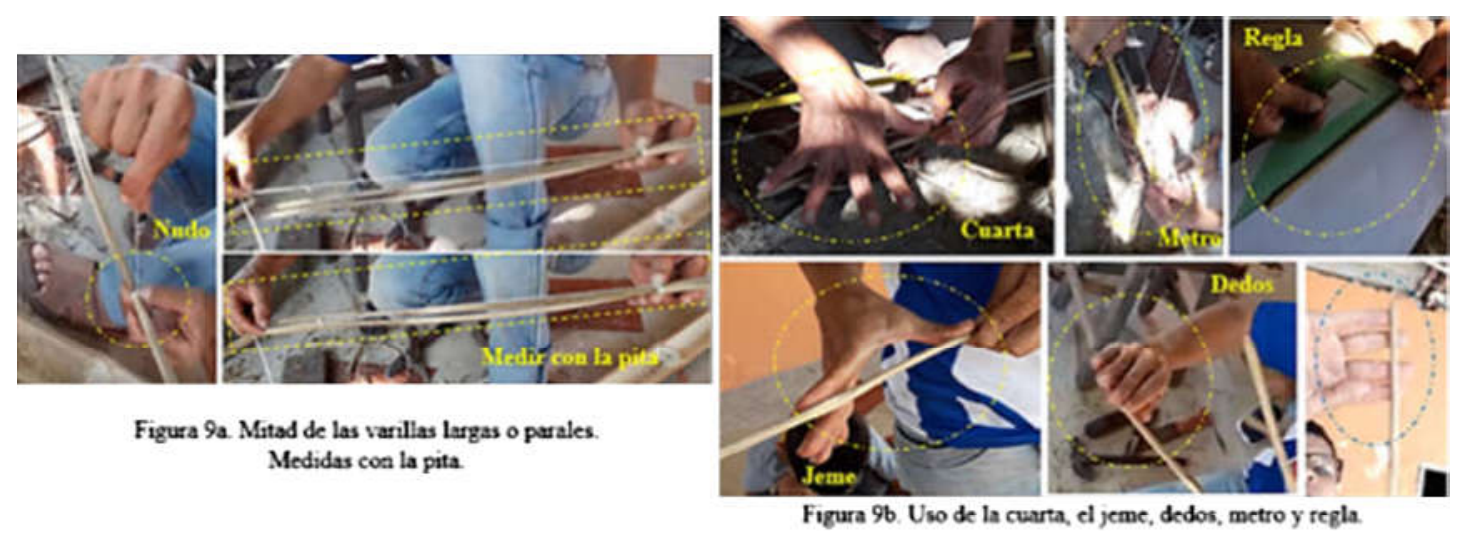

Figura 9. Usos de medidas no convencionales para las medidas de las varillas. Fuente: Elaboración del autor con información del trabajo de campo.

La medida con la pita emergió cuando P3 mencionó que las varillas largas de la cometa tenían cinco cuartas y el nudo tenía que quedar ubicado en el medio, es decir, a dos cuartas y media. Ahora bien, para saber cuánto era la media cuarta, P3 tomó la cuarta y la marcó en la varilla, luego tomó la misma medida con la pita por medio de la comparación (figura 10a) y después la dobló por la mitad, concluyendo que esa era la media cuarta (figura 10b).

\footnotetext{
6 Es de dos pitas, una la más larga que va amarrada de los dos lados del arco. La otra pita va amarrada en el centro de la cometa y luego le pone la altura para que la cometa se pueda elevar (audio 20200102_121637, minuto 11:05).

7 El jeme es la medida desde el dedo pulgar hasta el índice (audio 20200102-132648, minuto 00:23).
} 


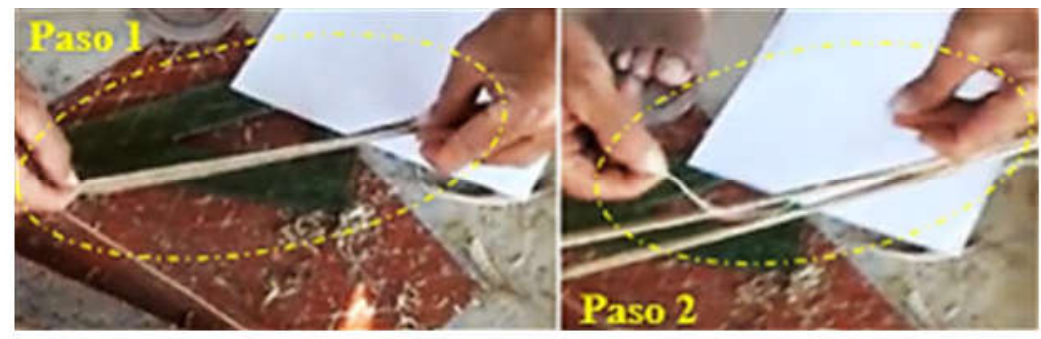

Figura 10a. Medida de la cuarta con la pita (comparación).

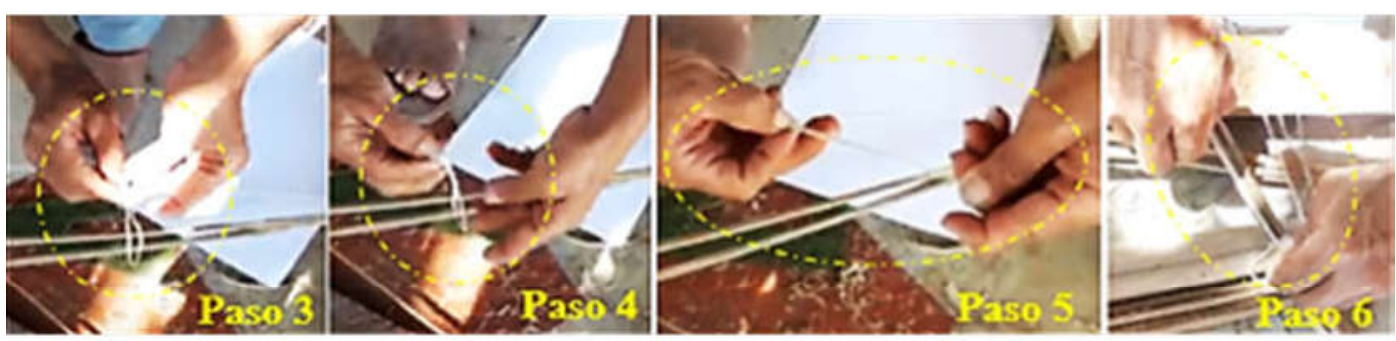

Figura 10b. Mitad de la pita.

Figura 10. Medida con la pita para hallar la mitad de la cuarta. Fuente: Elaboración del autor con información del trabajo de campo.

En la quinta fase, P3 colocó la varilla del centro sobre el nudo de la mitad de las varillas largas y midió con la pita, cuartas, jeme y dedos (figura 11a). Luego, en la sexta fase verificó que los lados de la cometa tuviesen igual medida, formándose seis triángulos isósceles, dos en la parte superior y dos en la parte inferior de la cometa (figura 11b). La séptima fase corresponde a forrar la cometa con papel.

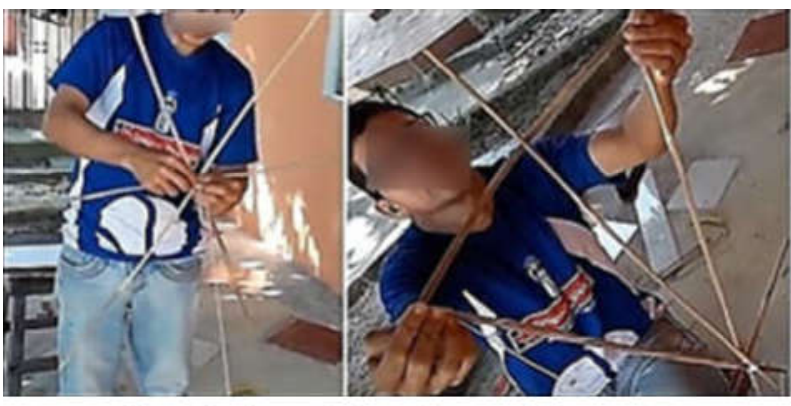

Figura lla. Amarre de las varillas: central, is que sostiene al arco y varilla atco

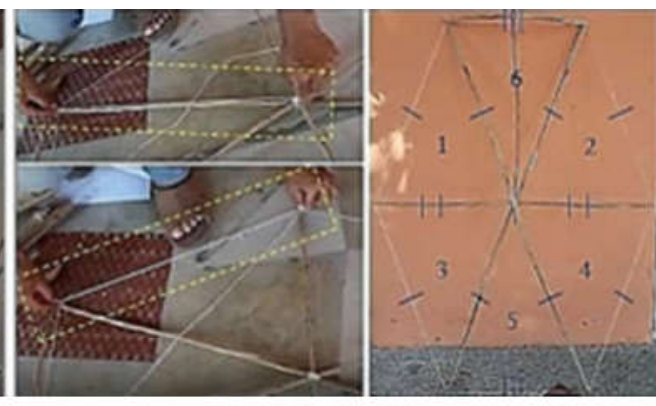

Figura 11b. Verificación de las medidas de los lados de la cometa

Figura 11. Armazón de la cometa y verificación de sus medidas. Fuente: Elaboración del autor con información del trabajo de campo.

En la elaboración de cometas se evidenciaron medidas no convencionales y convencionales usadas por P3, las cuales conforman su sistema de medida, por ejemplo, la cuarta, el jeme, los dedos, y solo se observaron conexiones internas en la equivalencia 1 cuarta es igual a 22 centímetros. Por último, P3 reconoció que la mitad de cinco cuartas es dos cuartas y media en un entorno no convencional. También 
usó la regla para verificar que la cuarta mide veintidós centímetros (ver el siguiente extracto de entrevista). En la tabla 4 se muestran las conexiones internas implícitas en las equivalencias y conversiones establecidas por P3.

E. ¿Cuánto tiene una cuarta?

P3. Depende, porque hay personas que tenemos la mano larga y otros que tenemos la mano pequeña. La cuarta mide veintidós centímetros.

E. ¿Cómo sabes tú?

P3. Porque yo la mido con un metro, veintidós centímetros.

Tabla 4. Conexiones entre unidades de medidas usadas por el cometero. ${ }^{8}$

Equivalencias y conversiones

1 cuarta $=22$ centímetros

$1 / 2$ cuarta $=11$ centrímetros

5 cuartas $=110$ centímetros

$1 / 2(5$ cuartas $)=2$ cuartas y $1 / 2$ cuarta
Conexiones internas

Conexión entre una unidad de medida no convencional y otra convencional

Fuente: Elaboración del autor con información del trabajo de campo.

En el análisis de la práctica de P3 se destaca la no-convencionalidad en sus procesos de medición, reconociendo aspectos importantes como: no todas las personas tenemos la cuarta con igual medida; en todas las medidas realizadas con la cuarta la mano debe quedar bien estirada; la cuarta no es una medida exacta, solo puede ser exacta si se mide con un metro o regla. Para validar esta información, ver el siguiente extracto de entrevista.

E. Primero usaste la cuarta y después una regla...

P3. Para que quedara en todo el centro [el nudo de pita en las varillas largas], porque la cuarta yo la abrí mucho.

E. ¿Cuándo mides con la cuarta qué sucede?

P3. Puede quedar muy abierta la cuarta o muy cerrada. Lo indicado es que quede bien abierta.

E. Entonces, ¿por qué usaste el metro o la regla?

P3. Para medir bien el centro de la varilla, para tener exactitud.

E. ¿Exactitud?

P3. Porque queda en todo el centro de la cometa.

E. ¿Con la regla obtienes exactitud?

P3. Exacto.

E. Y, ¿con las cuartas?

P3. A veces no, porque puede quedar muy larga o muy corta la cuarta. Con la regla medimos exactamente la cuarta, como aquí son cinco cuartas, para poder medir la mitad de la cuarta necesito una regla para saber cuánto mide la cuarta mía.

E. ¿Y si no existiera la regla?

P3. Tendría que usar una pita, mido en una varilla hasta donde llega la cuarta mía.

E. ¿Cuál es la diferencia entre medir con cuartas y medir con regla o metro?

8 Persona que elabora cometas. 
P3. Con la regla queda exacta, la medida queda exactamente porque tiene su numeración. Pero con la cuarta es una medida que uno tiene en la mente, una medida que uno tiene "al ojo".

\section{Sistema de medida en la elaboración de cajones voladores}

P4 mencionó que elabora los cajones en el mes de diciembre, usando la caña de bambú, pita y papel. También se deben seguir once fases. La primera es sacar seis varillas de caña de igual medida. Para P4 las varillas miden 83 centímetros, pero antes de medir con un metro, dijo que mide las varillas "al ojo", primero corta una varilla y esta la toma como unidad de medida para cortar las cinco varillas restantes con igual medida (figura 12a), es decir, establece un patrón de medida. Cuando P4 dijo "al ojo" se refirió a que la varilla podría medir 80 centímetros, casi un metro, enfatizando en que un metro es igual a la "altura del ombligo" y las varillas del cajón están por debajo del ombligo, es decir, ochenta centímetros (figura 12b).

En la fase dos, P4 cortó ocho varillas pequeñas de la misma medida, primero corta una y con base en esta corta las otras siete varillas. Posteriormente, en la fase tres, P4 mencionó que amarra los extremos de cuatro varillas entre sí y construye dos cuadrados con medidas iguales (ver figura 12c). En el siguiente extracto de entrevista se da evidencia de las tres primeras fases.

E. ¿Cuáles son las varillas?

P4. Las cuatro estas [1, 2, 3 y 4 en la figura 12a] y las dos estas del centro [5 y 6 en la figura 12a], cuatro de estas quedan paradas y las dos del centro cruzadas. También se sacan ocho varillas pequeñas del mismo grande, las mides.

E. ¿Cómo las mides?

P4. "Al ojo", del grande del cajón haces seis, si lo vas a hacer de un metro, sacas seis varillas de un metro, la guía es el alto del cajón y ocho de este grande [señaló la varilla pequeña]. Después, estas cuatro las amarras, luego las amarras aquí, haces el nudo, haces los dos cuadrados estos.

E. Cuándo hiciste así [E señaló el ombligo], ¿qué tuviste en cuenta?

P4. Para ver cuánto mide el cajón, aquí mide ochenta y cinco centímetros, le puse yo, y en realidad mide ochenta y tres centímetros, porque uno mide un metro [señaló la "altura del ombligo"], desde los pies hasta el ombligo hay un metro.

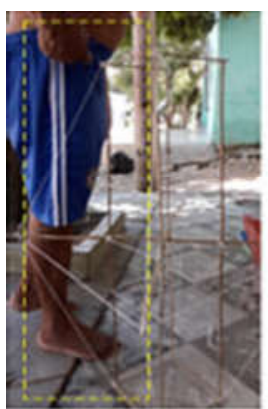

Figura $12 \mathrm{a}$. Medida de las varillas largas del cajón.

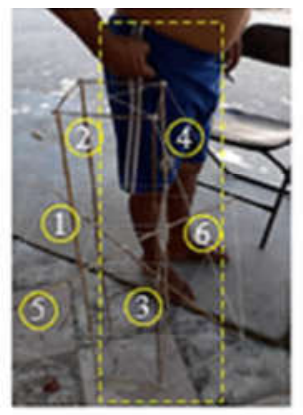

Figura 12. Construcción del cajón volador, varillas y amarres.

Fuente: Elaboración del autor con información del trabajo de campo.
Figura 12b. La altura del ombligo es igual a un metro.
Figura 12c. Varillas para la

conformación de cuadrados.
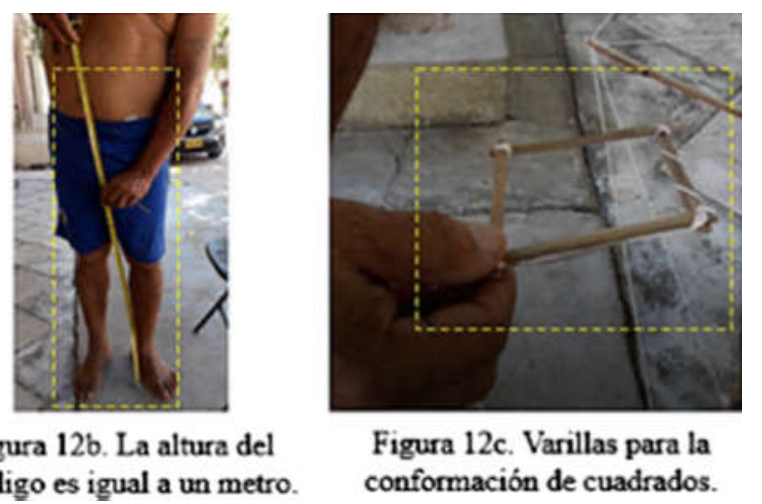
Después de haber construido los cuadrados, en la cuarta fase P4 sugirió que se debe medir para hallar el centro de las varillas. En este caso acude a "la pita" o "el palito"'. En la quinta fase, P4 mencionó que se deben usar dos de las varillas largas para hacer un bocachico, ${ }^{10}$ el cual se coloca en el centro de las cuatro varillas largas colocadas verticalmente. En particular, se hace otro bocachico pequeño construido a partir de la medida de las diagonales del cuadrado (figura 13a) para que sirva de modelo y se colocan marcas para que el bocachico grande quede centrado (figura 13b).

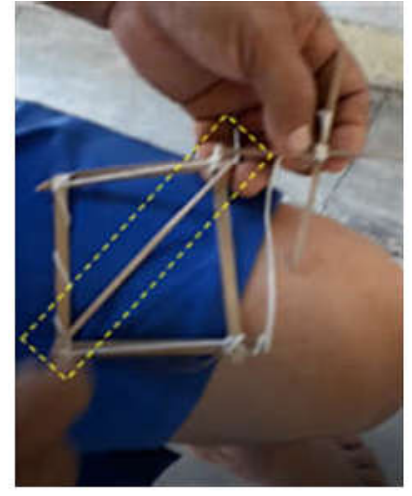

Figura 13a. Medida de la diagonal
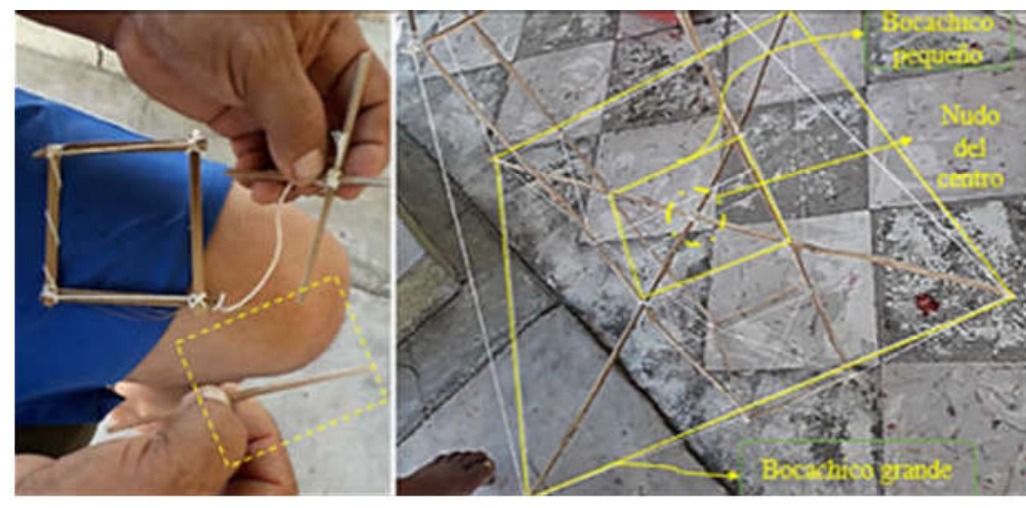

Figura 13b. Modelo de bocachico pequeño para centrar el bocachico grande.

Figura 13. Uso de la medida con "palito" para ubicar en el centro el bocachico grande. Fuente: Elaboración del autor con información del trabajo de campo.

En la sexta fase se refiere al amarre de las cuatro varillas en los dos cuadrados, cuya construcción corresponde a un paralelepípedo rectangular (figura 14a). Posteriormente, en la séptima fase, se amarra el bocachico grande en las varillas largas, a las cuales se les colocan unas marcas correspondientes al centro (figura 14b). La octava fase corresponde al amarre de las esquinas de los cuadrados con los extremos del bocachico grande (figura 14c).

En la novena fase, P4 enfatizó en la verificación de las medidas de los bordes del bocachico. En este caso, P4 afirmó que los bordes del bocachico deben tener igual medida, es decir, se conforma un cuadrado como en la figura $14 \mathrm{c}$ con color rojo. Dicha verificación se realiza midiendo con "la pita" (figura 15a). En la décima fase, P4 estableció medidas con el palito (patrón de medida equivalente a seis dedos) para ubicar dos pitas alrededor de las varillas largas, las cuales son equidistante respecto del centro de la varilla (figura 15b), cuya medida convencional es trece centímetros (ver extracto de entrevista, figura 15a y figura 15b).

\footnotetext{
9 Se usa como patrón de medida, de tal manera que el bocachico pequeño tenga medidas equidistantes desde el extremo hasta el centro.

10 Tipo de cometa conformada por dos varillas cruzadas.
} 


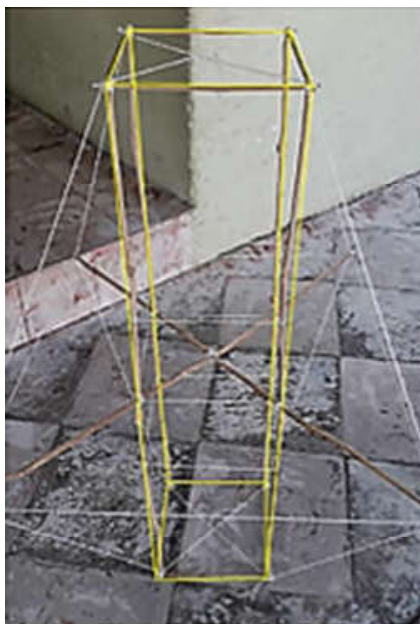

Figura 14a. Amarre de los cuadrados con las cuatro varillas largas.

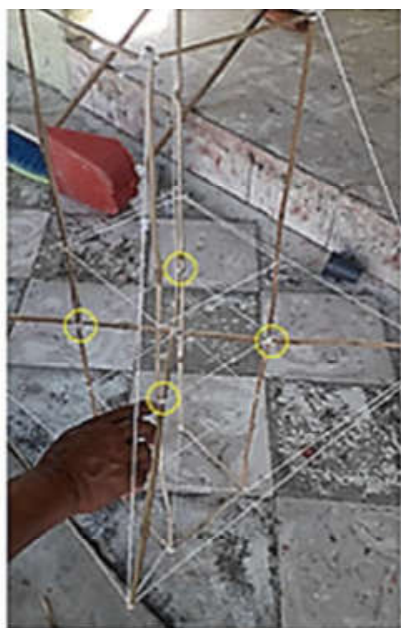

Figura 14b. Amarre del bocachico grande.

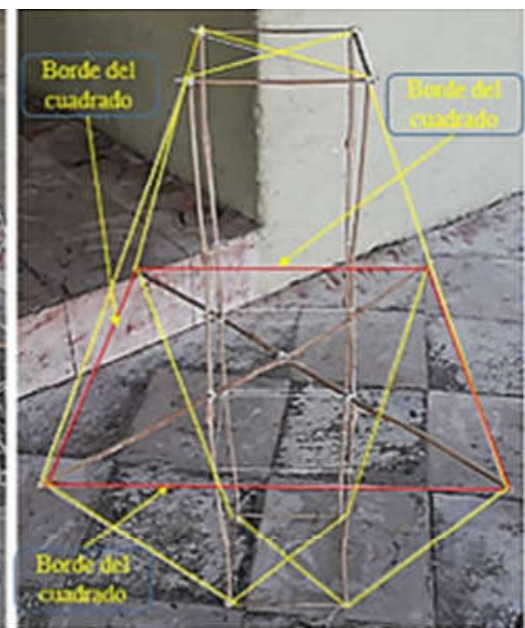

Figura 14c. Amarre de las esquinas de los cuadrados con el bocachico grande.

Figura 14. Amarres del cajón con pita para conformar los bordes. Fuente: Elaboración del autor con información del trabajo de campo.

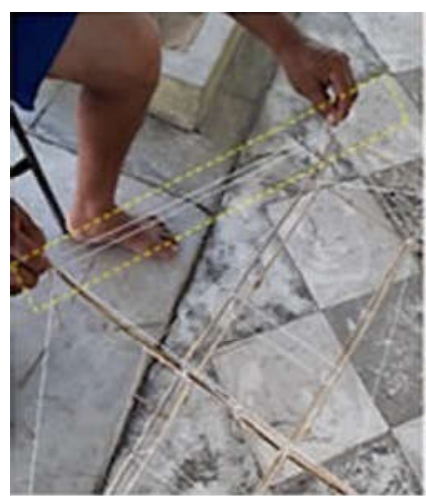

Figura 15a Verificación de los lados del cajón
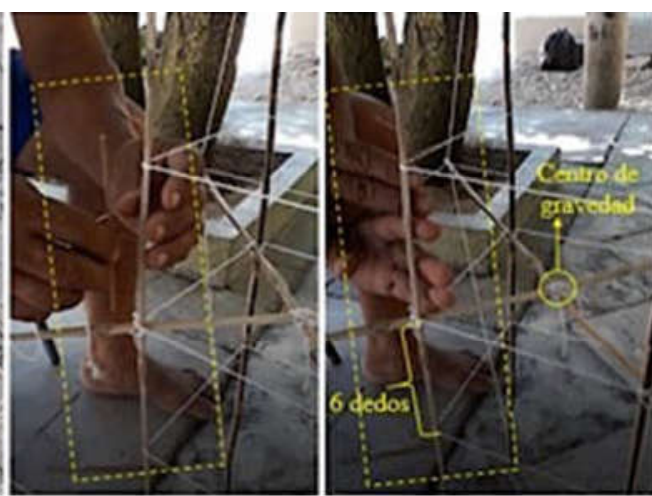

Figura 15b. Midiendo con el "palito" y dedos.

Figura 15. Verificación de las medidas del cajón y uso de los dedos y la pita como unidad de medida. Fuente: Elaboración del autor con información del trabajo de campo.

P4. Aquí mide cuarenta y ocho [cada borde del cajón], aquí tiene que medir cuarenta y ocho también. Este espacio de aquí [medida de seis dedos], en centímetros está en trece centímetros, trece para allá y trece para acá.

P4 mencionó que el centro del bocachico grande es el centro de gravedad del cajón para que se mantenga estable en el aire, además va ubicado en el centro de las varillas largas, como P4 dijo: "Si pones el cajón de noventa centímetros de altura, la mitad es cuarenta y cinco. Hay que tener en cuenta que el bocachico quede en la mitad de las cuatro varillas".

La fase once consiste en forrar el cajón con papel. Además, P4 enfatizó en los triángulos y en la medida de ángulos rectos que se observan en el cajón, reconociendo que miden noventa grados $\left(90^{\circ}\right.$; ver el siguiente extracto de audio). 
P4. Aquí tiene que medir noventa grados porque este es un ángulo recto. Donde se unen las dos varillas más rectas debe de quedar a escuadra.

En la tabla 5 se presentan las conexiones internas que se promueven en las equivalencias y conversiones entre unidades de medida identificadas en la elaboración del cajón.

Tabla 5. Conexiones entre unidades de medidas usadas en la elaboración del cajón.

Equivalencias y conversiones

Una varilla larga $=83$ centímetros

Una varilla corta $=20$ centímetros

Un borde del cajón $=48$ centímetros

Seis dedos $=13$ centímetros

Pita (borde) $=48$ centímetros

Palito (seis dedos) $=13$ centímetros

Altura del ombligo $=$ un metro

$1 / 2$ altura del ombligo $=50$ centímetros
Conexiones internas

Conexión entre una unidad de medida no convencional y otra convencional

$$
\text { Palito }=\text { seis dedos }
$$

Conexión entre unidades de medida no convencionales

Fuente: Elaboración del autor con información del trabajo de campo.

\section{Sistema de medida en la práctica de la soldadura eléctrica}

P5 y P6 hicieron énfasis en “¿Cómo se promueve la soldadura?” y "¿Qué aspectos son indispensables para soldar?”. Por su parte P5 se ha destacado por su trabajo en latonería y soldadura. P6 es egresado de una institución técnica industrial. Ellos no enfatizaron en la construcción de una estructura específica, pero dieron un panorama general del arco eléctrico.

En el caso de P5, mencionó que para hacer un cordón de soldadura se debe hacer buen arco eléctrico, el cual consiste en poner en contacto el electrodo con el material y, después que haga arco eléctrico, mantenerlos a una distancia de menos de medio centímetro (ver extracto de entrevista y figura 16a). Además sugirió que la mano debe hacer un movimiento ondulatorio ("como si estuvieras escribiendo") y tener pulso. P5 hizo referencia a que el electrodo debe penetrar el material cuando se vayan a hacer cortes con soldadura (figura 16b).
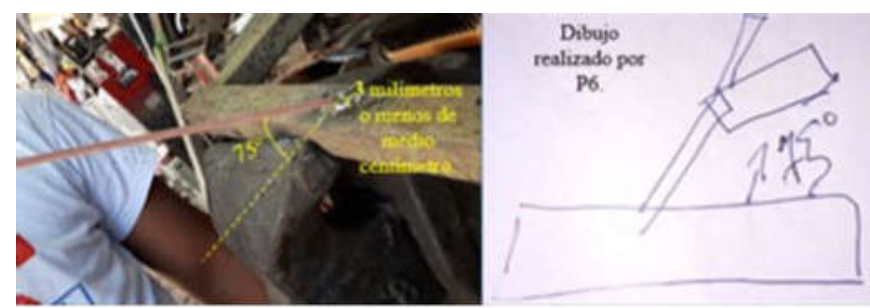

Figura 16a. Distancia entre el electrodo y la pieza: $3 \mathrm{~mm}$ o menos de medio centimetro

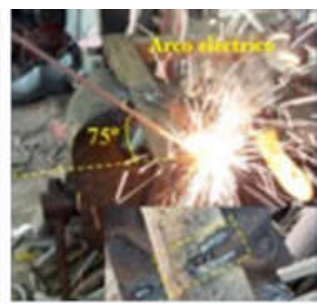

Figura 16b. Corte con roldadura

Figura 16. Consecución del arco eléctrico y ubicación del electrodo. Fuente: Elaboración del autor con información del trabajo de campo. 
P5. Para hacer el arco eléctrico hay que tener el electrodo menos de medio centímetro. Otra cosa es tener el pulso, debe mantenerse menos de medio centímetro. Si vas a tirar cordón de soldadura, la mano debe hacer ondulaciones.

Por su parte, P6 dice que el electrodo debe quedar separado del material tres milímetros y con una inclinación cómoda para el trabajador, pero que normalmente se debe considerar un ángulo de setenta y cinco grados entre la pieza a soldar y el electrodo (figuras 16a y 16b; ver extracto de entrevista).

E. ¿Cuánto tiene la separación...?

P6. Tres milímetros.

E. O sea, la separación desde la pieza...

P6. Al electrodo.

E. La inclinación que ustedes le dan al electrodo, ¿hay una inclinación recomendada?

P6. Setenta y cinco grados.

P6 y P5 sostienen que no todas las veces el electrodo formará un ángulo de $75^{\circ}$ con la pieza, sino que todo depende de la pieza a soldar. Por ejemplo, la soldadura sobre cabeza. En este sentido, P6 demostró que ha usado la escuadra para la medida de ángulos. Se infirió esta información por lo que P6 dijo: "Aquí la escuadra te marca setenta y cinco grados (dibujó), pero cuando vayas a soldar no vas a buscar la escuadra, por eso es como te acomodes". Otros aspectos fundamentales en la soldadura son los cortes, biseles y chaflanes (ver el extracto de entrevista).

E. Hay materiales planos y otros con diagonales, ¿cómo ustedes hacen eso?

P6. Bisel, chaflán.

P5. Para los cortes en ángulo.

P6. Eso es para materiales gruesos, donde la soldadura no penetra, le haces un bisel, tiene que quedar de dos milímetros de grueso.

En otras explicaciones dadas por P6 aparecieron nociones de unidades de medidas convencionales cuando hizo referencia a la abertura de "un octavo" entre dos piezas, la cual se puede medir de manera no convencional con la punta de un electrodo o con el ancho de dos monedas de cien pesos (figura 17).

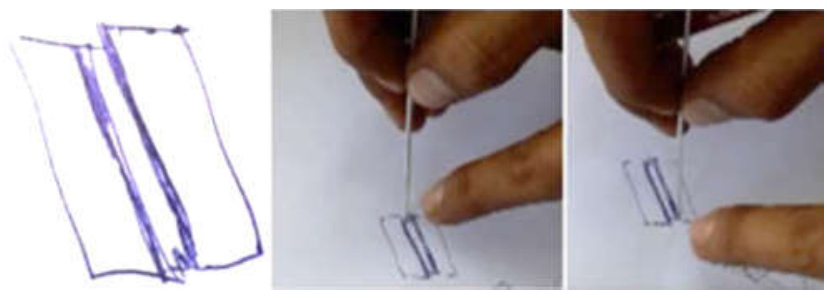

Figura 17. El ancho de un electrodo y el ancho de dos monedas (medidas no convencionales). Fuente: Elaboración del autor con información del trabajo de campo.

Las unidades de medidas evidenciadas en la labor del soldador fueron el milímetro, el grado, el ancho de la punta del electrodo o de dos monedas juntas; además se 
infirió la equivalencia dos milímetros $=$ ancho de la punta del electrodo $=$ ancho de dos monedas juntas $=$ un octavo.

\section{Sistema de medida en la agricultura}

P7 y P8 han desarrollado conocimientos ancestrales que les ayudan a ejercer sus labores. En dichos conocimientos se evidenciaron procesos de medición como se presentan a continuación: P7 y P8 enfatizaron en la elaboración de una "rosa" o cultivo de plantas de maíz, yuca y guandú (Cajanus cajan); como mencionó P8 "en términos campesinos, un cultivo se llama rosa". Para el caso del sembrado de yuca, los agricultores coincidieron en que en una hectárea de tierra se siembran diez mil plantas de yuca, separadas a una distancia de un metro (figura 18).

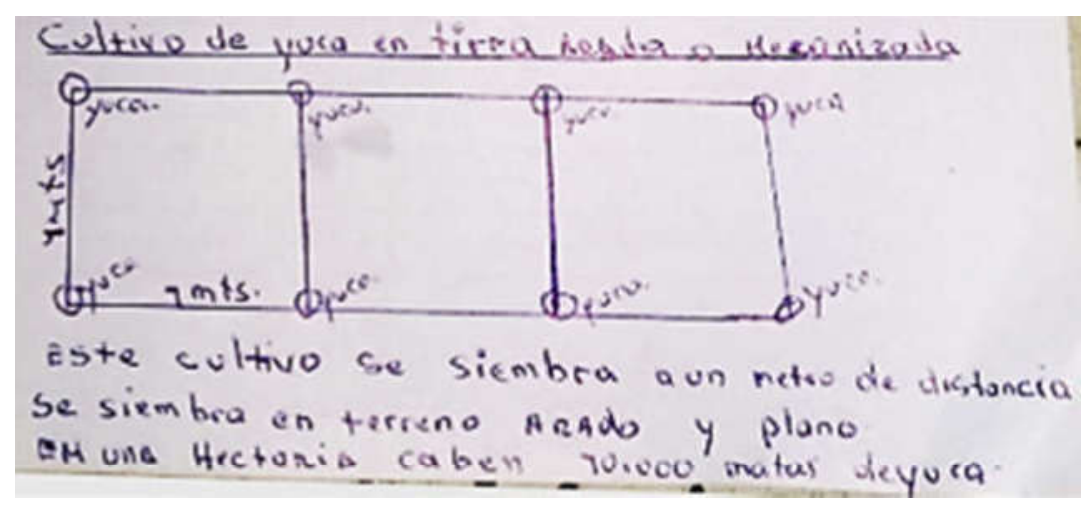

Figura 18. Medidas usadas en la construcción de un rosa (explicación de P8). Fuente: Elaboración del autor con información del trabajo de campo.

Otro rosa es donde siembran guandú, yuca y maíz, clasificándose en dos tipos de siembra: carrera en blanco y tranco en blanco (ver explicación en el extracto de entrevista y figura 19a).

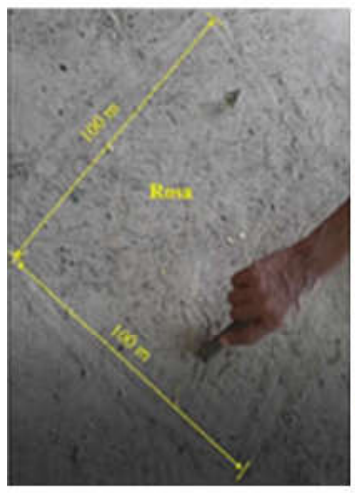

Figura 19a. Carrera en blanco.

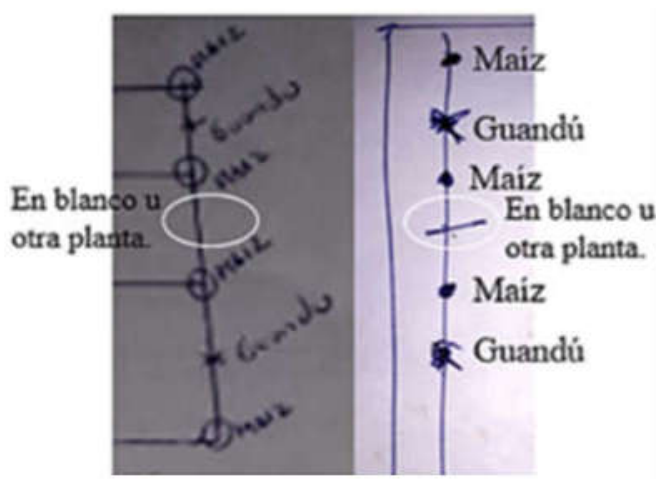

Figura 19b. Tranco en blanco.

Figura 19. Tipos de rosa y medidas.

Fuente: Elaboración del autor con información del trabajo de campo. 
E. ¿Cuántos palos de yuca caben aquí?

P7. Diez mil palos de yuca en una hectárea. Es un sistema, eso lo siembran en la rosa a un metro de distancia. Esto es una hectárea de tierra [dibujó], yo empiezo aquí una carrera de yuca y maíz.

E. ¿Cómo las ubica?

P7. Un palo de yuca, uno de maíz, uno de yuca, uno de maíz... hasta terminar la carrera. Aquí empiezo con guandú, yuca, guandú, yuca, no siembro maíz. Después en la otra carrera coloco lo mismo que en la primera, maíz, yuca... esto se llama en el idioma de la rosa, carrera en blanco.

E. Y, ¿la tranco en blanco?

P7. Tú siembras maíz, guandú, aquí tocaría maíz, aquí viene el guandú, entonces no sembramos guandú [queda en blanco]. Luego, viene el maíz y el guandú, entonces, a esto se le llama tranco en blanco [figura 19b].

P7 menciona que en las siembras medían con una vara equivalente a dos metros. Esta vara es usada por muchos campesinos y también es igual a una braza. Además se reconoció la unidad de medida de "un cincuenta" equivalente a cien metros (ver extracto de audio y figura 20).

P7. "Un cincuenta" son cien metros. Las personas cogían una braza con un palo, medían una braza, que son dos metros, o si no medían esta vara... [la persona en pie con la mano hacia arriba], son dos metros.
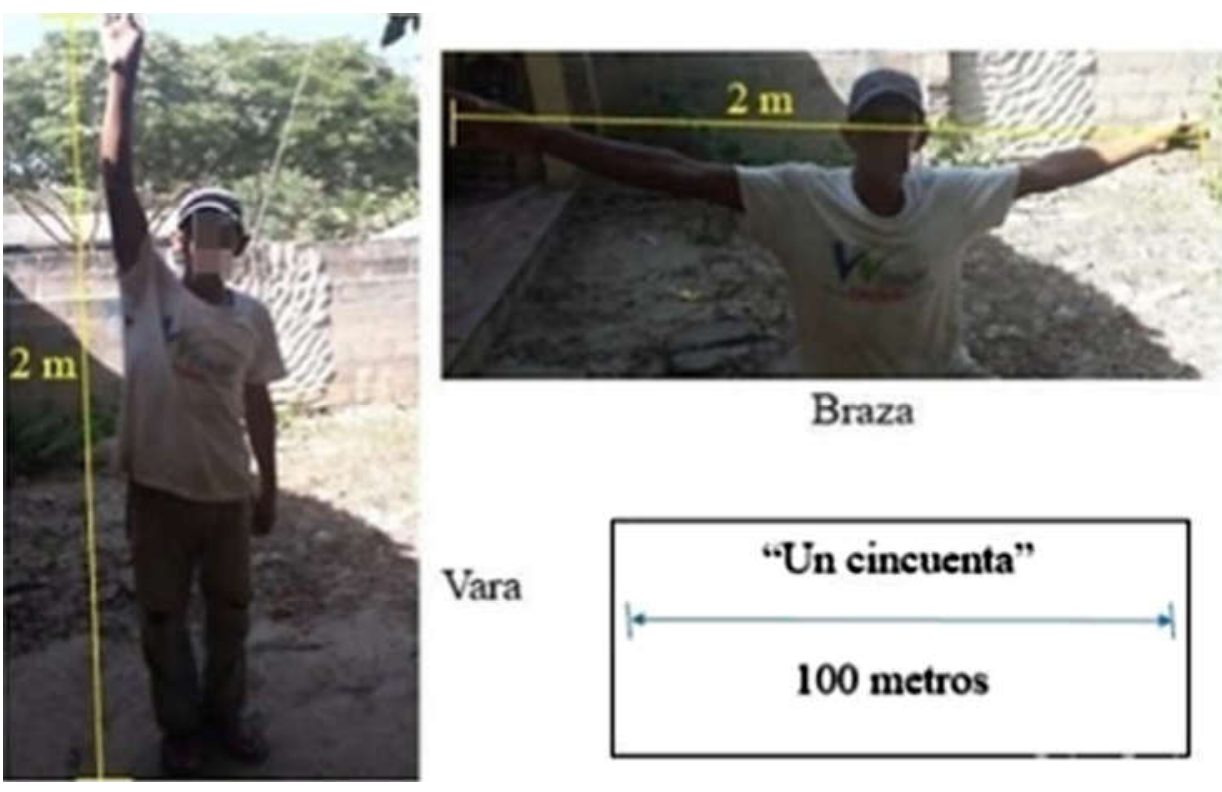

Braza

Figura 20. Equivalencia de unidades de medida no convencionales (braza y vara). Fuente: Elaboración del autor con información del trabajo de campo.

P8 mencionó que "un cincuenta" es igual a cien metros y equivalente a cincuenta brazas. También P8 mencionó "se mide el tranco de uno mismo, como cuando el árbitro mide los once pasos para el penal, es decir, un tranco es igual a un metro". 
En la tabla 6 se presentan las conexiones evidenciadas en la labor de los agricultores.

Tabla 6. Conexiones entre unidades de medidas usadas en la agricultura.

Equivalencia y conversiones

Conexiones internas

\begin{tabular}{cc}
\hline 1 tranco $=1$ metro & \\
\hline 1 braza $=2$ metros & Conexión entre una unidad de medida no convencional y otra convencional \\
$1 / 2$ braza $=1$ metro & \\
1 vara $=2$ metros & \\
Un cincuenta $=100$ metros & Conexión entre unidades de medida no convencionales \\
\hline 1 braza $=1$ vara & \\
\hline Un cincuenta $=50$ brazas
\end{tabular}

Fuente: Elaboración del autor con información del trabajo de campo.

\section{Sistema de medida en la ganadería}

En relación con la ganadería, se logró reconocer una unidad de medida usada por P8 cuando se refirió a que en la venta de leche de vaca usan dos recipientes (calambucos), los cuales tienen una capacidad de 20 y 40 litros. También P8 mencionó que una vaca lechera produce diez litros de leche por día, durante un periodo de seis meses. En este sentido, se infiere que dos ordeños llenan un calambuco de veinte litros, cuatro ordeños llenas un calambuco de cuarenta litros. Además se estable la relación: un calambuco de 40 litros es dos veces la capacidad del calambuco de 20 litros (figura 21).

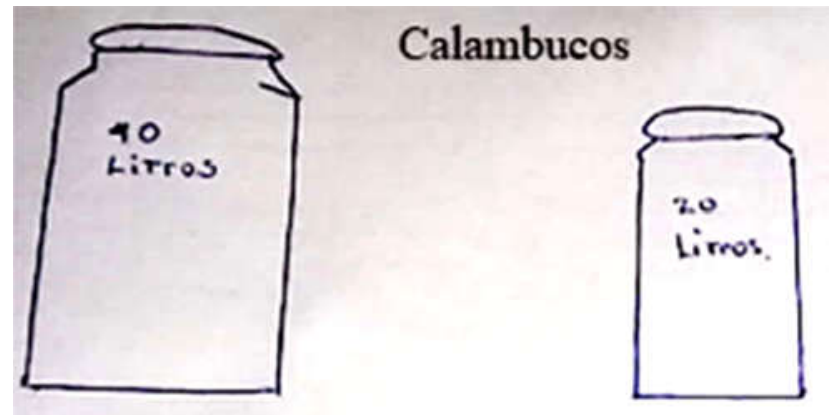

Figura 21. Unidad de medida usada por P8 en la producción de leche. Fuente: Elaboración del autor con información del trabajo de campo.

Otra unidad de medida usada por P8 es la arroba, equivalente a 25 libras, y mencionó que el peso de la vaca oscila entre 300 y 400 kilos.

\section{Conexiones externas entre los sistemas de medidas}

En este estudio, las conexiones externas se promueven cuando una unidad de medida (convencional o no convencional) es usada de manera similar en diferentes sistemas de medidas de prácticas cotidianas distintas. Por ejemplo, la unidad de medida de longitud "altura del ombligo" es usada en la ebanistería, en la elaboración de bollos 
y cajones voladores, donde los artesanos le dan la misma equivalencia, "un metro", igual uso e incluso manejan el mismo lenguaje, es decir, tienen el mismo significado. Por lo tanto, se puede decir que existe una conexión externa (figura 22).

Cabe destacar que la "altura del ombligo" es usada para medir longitudes, por ejemplo, en la ebanistería la emplean para instalar cerraduras; en la elaboración de bollos la usan para medir la pita, y en la elaboración de cajones para medir las varillas. Otras investigaciones usaron la "altura del ombligo" para mediciones en la albañilería (Rey y Aroca, 2011). En la tabla 7 se sintetizan las conexiones externas evidenciadas en los sistemas de medidas de las diferentes prácticas cotidianas.

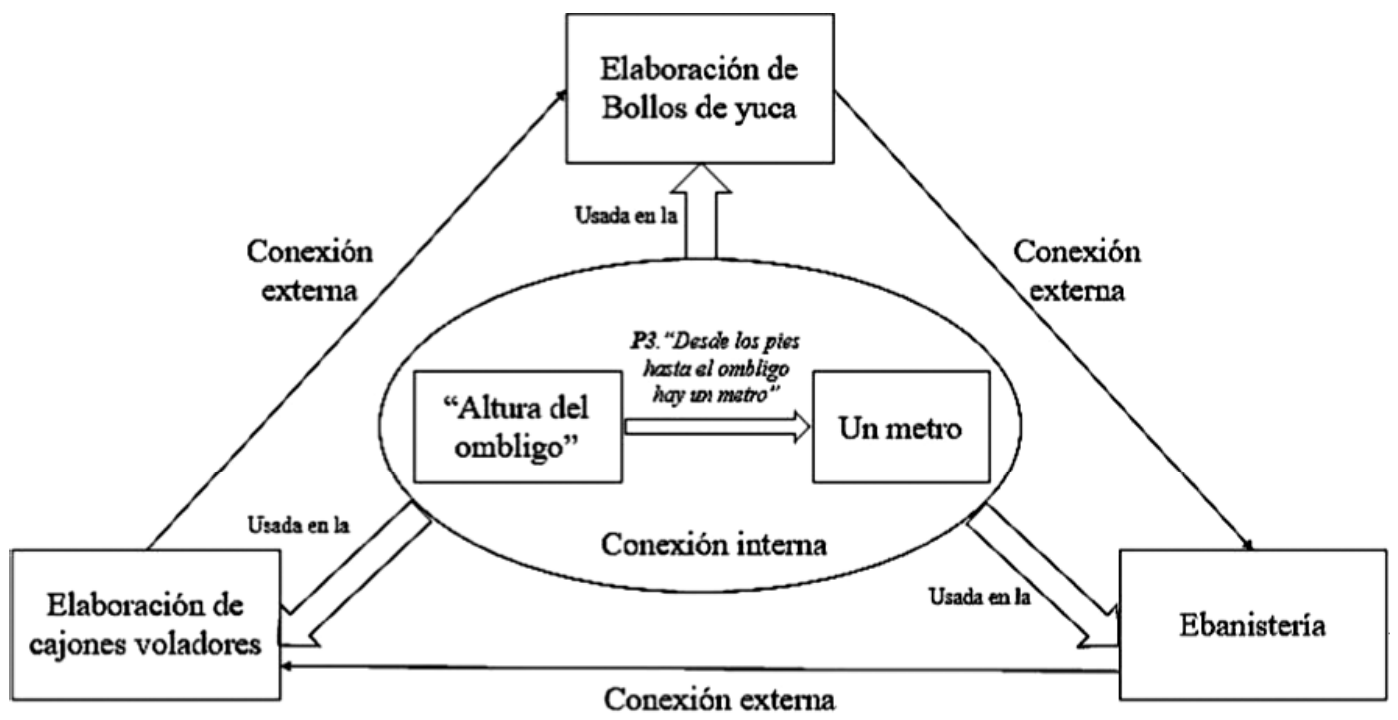

Figura 22. Sistemas de medidas de prácticas cotidianas conectados por el uso de la unidad de medida "altura del ombligo". Fuente: Elaboración del autor con adaptaciones de Rodríguez-Nieto, Rodríguez-Vásquez y Font, 2020.

Tabla 7. Conexiones externas entre sistemas de medidas.

Unidad de medida generadora de la conexión externa

\begin{tabular}{cr}
\hline Altura del ombligo (figura 22) & Elaboración de cometas y bollos y ebanistería \\
\hline Cuarta & Elaboración de cometas y ebanistería \\
\hline Jeme & Elaboración de bollos y cometas \\
\hline $\begin{array}{c}\text { Dedos } \\
\text { Pita }\end{array}$ & Elaboración de cometas y cajones \\
\hline Braza & Elaboración de bollos, agricultura \\
\hline Litro & Elaboración de bollos y ganadería \\
\hline Libra & Ebanistería, elaboración de cajones y soldadura \\
\hline Grados & Ebanistería, soldadura, elaboración de bollos, cometas y cajones \\
\hline Centímetro & Soldadura, ebanistería, elaboración de cometas y cajones, agricultura \\
\hline Milímetro & Ebanistería, agricultura, soldadura, elaboración de cajones, cometas y bollos \\
\hline Metro & Fuente: Elaboración del autor con información del trabajo de campo,
\end{tabular}

Prácticas cotidianas con sistemas de medidas conectados 
P3 y P4 mencionaron que usan la medida "al ojo" pero realmente es un proceso de estimación (Rey y Aroca, 2011) que, en muchos casos, es previo a la medición, por ejemplo, cuando P4 estimó el tamaño de las varillas del cajón.

\section{DisCuSIÓN Y CONCLUSIONES}

En esta investigación se presentaron las conexiones entre los diversos sistemas de medidas desarrollados por artesanos del municipio de Baranoa. Dichas conexiones fueron denominadas internas y externas. También se evidenciaron las conexiones entre las matemáticas y las matemáticas desarrolladas localmente por grupos culturales, coincidiendo con Rosa y Orey (2018). Se considera que las conexiones internas y externas podrían usarse como una herramienta para analizar las conexiones entre sistemas de medidas que emergen en prácticas cotidianas. Además se evidencian conexiones de significado, por ejemplo, cuando P3 atribuye un sentido a la cuarta como "la medida [...] 'del dedo pulgar al meñique' abierta la mano", o bien, cuando P4 menciona que la altura del ombligo es "la medida desde los pies hasta el ombligo y hay un metro". En este contexto se hace referencia a una conexión de significado, dado que estas se identifican "cuando un sujeto atribuye un sentido a un concepto matemático, es decir, lo que significa para él (que lo diferencia de los demás)" (García-García, 2019; García-García y Dolores-Flores, 2020). De forma general, en esta investigación emergieron tres tipos de conexiones: internas, externas y de significado para el análisis de las conexiones desde una perspectiva etnomatemática y los sistemas de medidas.

Los resultados obtenidos son significativos, dado que en algunas investigaciones (e.g., Chieus, 2009; Rey y Aroca, 2011; Rodríguez-Nieto, Mosquera y Aroca, 2019) también se han explorado formas de medir de grupos culturales con resultados importantes, pero por separado. En este trabajo se propuso articular, conectar los conocimientos que emergen de las personas cuando explican lo que hacen en su cotidianidad, lo cual es uno de los objetivos de los estudios etnomatemáticos (Barton, 1996; D'Ambrosio, 2014), con miras a incidir en la enseñanza y aprendizaje de los sistemas de medición en las clases de matemáticas. De esta manera se coincide con el NCTM (2000) cuando afirman que se deben hacer "conexiones dentro de las matemáticas y entre las matemáticas y las áreas fuera de las matemáticas” (p. 44).

En este estudio se concuerda con algunos trabajos que han reportado el uso de unidades de medidas no convencionales como la cuarta, el jeme, dedos, braza, la altura del ombligo, entre otras (e.g., Pérez, 1978; Palerm y Chairez, 2002; Chieus, 2009; Rey y Aroca, 2011; Mosquera, Rodríguez-Nieto y Suárez, 2015; Muhtadi et al., 2017; Trujillo, Miranda y De la Hoz, 2018; Rodríguez-Nieto, Mosquera y Aroca, 2019). Sin embargo, con estos resultados se aspira a diseñar tareas que involucren los sistemas de medidas conectados, donde se promuevan conexiones en el aula de clases, donde los estudiantes hagan conversiones y reconozcan equivalencias. Cabe destacar que 
en Trujillo, Miranda y De la Hoz (2018) se evidenciaron relaciones entre sistemas de medidas, pero no enfatizaron en tipos de conexiones internas y externas.

Por otro lado, uno de los retos de las investigaciones enmarcadas en la etnomatemática es llevar los conocimientos explorados en un grupo cultural al aula de clases. Se han realizado algunos trabajos que han incidido significativamente en el aula (e.g., Mosquera, Rodríguez-Nieto y Suárez, 2015) con una práctica cotidiana de un contexto particular. Pero en este trabajo se logró reconocer un tema matemático en diversas prácticas para tener más posibilidades de aplicarlos y conectarlos con los estudiantes, por eso se enfatizó en las conexiones externas. Por ejemplo, los profesores pueden usar artefactos (la cometa, el cajón) que les permitan diseñar situaciones didácticas y a los estudiantes conocer mayor aplicabilidad de las matemáticas en su contexto sociocultural y establecer conexiones, dado que son importantes para lograr compresión de conceptos matemáticos (García-García, 2019).

A pesar de que cada grupo cultural desarrolla su propia matemática (Gerdes, 2013), se asegura que los resultados de este trabajo pueden contribuir a personas, estudiantes, profesores y artesanos de otros grupos culturales. Se sugiere lo anterior dado que la temática abordada no se desconoce en otros ambientes culturales, por ejemplo, en Brasil (e.g., Oliveira Júnior y Mendes dos Santos, 2016), en México (e.g., Ávila, 2014; García-García y Bernandino-Silverio, 2019), en Chile (e.g., AravenaPacheco, Loncomilla-Gallardo y Pizarro-Cisternas, 2020) y en otros países (e.g., Supiyati, Hanum y Jailani, 2019), dejando ver que esta investigación podría ser útil para la comunidad académica internacional.

\section{Agradecimientos}

A los artesanos Wilson, Fauto, Carlos, José, Sigifredo, Jesús y su familia, Ramiro y Arturo por suministrar la información para el desarrollo de esta investigación. A Julitsha, Idamis, Etel, Ana, Yadira y Ramiro Jr. por su colaboración en la comunicación con los artesanos. A CONACyT por apoyarme económicamente en mis estudios doctorales en Ciencias con especialidad en Matemática Educativa en la Universidad Autónoma de Guerrero, México.

\section{REFERENCIAS}

Alsina, Á. (2012). Más allá de los contenidos, los procesos matemáticos en educación infantil. Edma 0-6, Educación Matemática en la Infancia, 1(1), 1-14.

Ameigeiras, A. R. (2006). El abordaje etnográfico en la investigación social. En I. Vasilachis de Gialdino (ed.), Estrategias cualitativas de investigación (pp. 107151). Buenos Aires: Gedisa.
Aravena-Pacheco, L., Loncomilla-Gallardo, A., y PizarroCisternas, D. (2020). Nociones matemáticas en la construcción de muebles. Estudio de caso con un mueblista del sur de Chile [Tesis de pregrado]. Universidad Austral de Chile, Puerto Montt.

Aroca, A. (2016). La definición etimológica de etnomatemática e implicaciones en educación matemática. Educación matemática, 28(2), 175-195. 
Ávila, A. (2014). La etnomatemática en la educación indígena: así se concibe, así se pone en práctica. Revista Latinoamericana de Etnomatemática, 7(1), 19-49.

Barton, B. (1996). Making sense of ethnomathematics: Ethnomathematics is making sense. Educational Studies in Mathematics, 31(1-2), 201-33.

Bishop, A. (1999). Enculturación matemática. La educación matemática desde una perspectiva cultural. Barcelona: Paidós.

Businskas, A. M. (2008). Conversations about connections: How secondary mathematics teachers conceptualize and contend with mathematical connections [Tesis de doctorado inédita]. Simon Fraser University. Canada.

Castaño, J. (2015). El libro de los pesos y medidas. Madrid: La Esfera de los Libros.

Castro-Inostroza, A., Rodríguez-Nieto, C. A., AravenaPacheco, L., Loncomilla-Gallardo, A., y PizarroCisternas, D. (2020). Nociones matemáticas evidenciadas en la práctica cotidiana de un carpintero del sur de Chile. Revista Cientifica, 39(3). https://doi. org/10.14483/23448350.16270.

Chieus, G. (2009). A Braça da Rede, uma Técnica Caiçara de Medir. Revista Latinoamericana de Etnomatemática, 2(2), 4-17.

D'Ambrosio, U. (2001). Etnomatemática: Elo entre las tradiçoes e a modernidad. Colección: Tendencias en educación matemática. Belo Horizonte: Autêtica.

D’Ambrosio, U. (2014). Las bases conceptuales del Programa Etnomatemática. Revista Latinoamericana de Etnomatemática, 7(2), 100-107.

D’Ambrosio, U., y Knijnik, G. (2020). Encyclopedia of Mathematics Education. En S. Lerman (ed.), Ethnomathematics (pp. 283-288). Suiza: Springer Nature.

Dolores-Flores, C., y García-García, J. (2017). Conexiones intramatemáticas y extramatemáticas que se producen al resolver problemas de cálculo en contexto: un estudio de casos en el nivel superior. Bolema. Boletim de Educação Matemática, 31(57), 158-180.

García-García, J. G. (2019). Escenarios de exploración de conexiones matemáticas. Números: Revista de Didáctica de las Matemáticas, 100, 129-133.

García-García, J., y Bernandino-Silverio, N. (2019). Conocimientos geométricos en la elaboración de un artefacto en una comunidad Nuu savi. IE Revista de Investigación Educativa de la REDIECH, 10(19), 105-120.
García-García, J., y Dolores-Flores, C. (2020). Exploring pre-university students' mathematical connections when solving Calculus application problems, International Journal of Mathematical Education in Science and Technology. DOI: 10.1080/0020739X.2020.1729429.

Gerdes, P. (2013). Geometría y cestería de los Bora en la Amazonía peruana. Lima: Ministerio de Educación.

Godino, J. D., Batanero, C., y Roa, R. (2002). Medida de magnitudes y su didácticapara maestros. Universidad de Granada, Departamento de Didáctica de la Matemática.

Hernández, R., Fernández, C., y Baptista, P. (2014). Metodologia de la investigación. México: McGraw-Hill.

Kula, W. (1980). Las medidas y los hombres (3a. ed.). Madrid: Siglo XXI de España.

Longhurst, R. (2010). Semi-structured interviews and focus groups. En N. Clifford, S. French, y G. Valentine (eds.), Key Methods in Geography (pp. 103-115). Londres: Sage.

Madusise, S. (2015). Cultural villages as contexts for mediating culture and mathematics education in the South African curriculum. Revista Latinoamericana de Etnomatemática, 8(2), 11-31.

Mosquera, G., Rodríguez-Nieto, C., y Suárez, S. (2015). Dos sistemas de medidas no convencionales en la pesca artesanal con cometas en bocas de ceniza y su potencial para la educación matemática [Tesis de pregrado]. Universidad del Atlántico, Barranquilla, Colombia.

Muhtadi, D., Sukirwan, Warsito, y Prahmana, R.C.I. (2017). Sundanese ethnomathematics: Mathematical activities in estimating, measuring, and making patterns. Journal on Mathematics Education, 8(2), 185-198.

National Council of Teachers of Mathematics (NCTM) (2000). Principles and standards for school mathematics. Reston: National Council of Teachers of Mathematics.

Oliveira Júnior, B., y Mendes dos Santos, E. (2016). Etnomatemática: $\mathrm{O}$ ensino de medida de comprimento no $6^{\circ}$ ano do ensino fundamental na Escola Indígena Kanamari Maraã-AM, Brasil. Revista Latinoamericana de Etnomatemática, 9(2), 53-66.

Palerm, J., y Chairez, C. (2002). Medidas antiguas de agua. Relaciones. Revista del Colegio de Michoacán, 23(92), 227 251.

Pérez, G. (1978). Metrología y medidas agrimensales en Aragón a fines del Antiguo Régimen. Cuadernos Aragoneses de Economía, Universidad de Zaragoza, 103-118. 
Real Academia Española (RAE) (2018). Diccionario de la lengua española. Madrid, España: Autor.

Rey, M., y Aroca, A. (2011). Medición y estimación de los albañiles, un aporte a la educación matemática. Revista U.D.C.A Actualidad \& Divulgación Cientifica, 14(1), 137-147.

Rodríguez-Nieto, C., Morales, L., Muñoz, A., y Navarro, C. (2017). Medidas no convencionales: el caso del mercado Baltazar R. Leyva Mancilla, Chilpancingo, Gro. En Federación Española de Sociedades de Profesores de Matemáticas (eds.), VIII Congreso Iberoamericano de Educación Matemática (pp. 225-233). Madrid, España.

Rodríguez-Nieto, C., Mosquera, G., y Aroca, A. (2019). Dos sistemas de medidas no convencionales en la pesca artesanal con cometa en Bocas de Cenizas. Revista Latinoamericana de Etnomatemática, 12(1), 6-24.

Rodríguez-Nieto, C., Aroca, A., y Rodríguez-Vásquez, F. M. (2019). Procesos de medición en una práctica artesanal del caribe colombiano. Un estudio desde la etnomatemática. Revista Latinoamericana de Etnomatemática, 12(4), 61-88. DOI: 10.22267/ relatem.19124.36.
Rodríguez-Nieto, C., Rodríguez-Vásquez, F. M., y Font, V. (2020). A new view about connections. The mathematical connections established by a teacher when teaching the derivative. International Journal of Mathematical Education in Science and Technology, DOI: 10.1080/0020739X.2020.1799254.

Rosa, M., y Orey, D. (2018). Propondo um currículo trívium fundamentado nas perspectivas da Etnomatemática e da modelagem. Revista Educação Matemática en Foco, 7(2), 63-98.

Sandoval, C. (2002). Investigación cualitativa. Bogotá: ARFO Editores e Impresiones Ltda.

Secretaria da Educação (2012). Currículo do Estado de São Paulo: matemática e suas tecnologias. Secretaria da Educação, São Paulo, Brasil.

Supiyati, S., Hanum, F., y Jailani, J. (2019). Ethnomathematics in Sasaknese Architecture. Journal on Mathematics Education, 10(1), 47-58.

Trujillo, O., Miranda, I., y De la Hoz, E. (2018). Los sistemas de medida en la comunidad Arhuaca: su uso en distintos contextos. Revista Latinoamericana de Etnomatemática, 11(2), 31-51.

Cómo citar este artículo:

Rodríguez-Nieto, C. A. (2020). Explorando las conexiones entre sistemas de medidas usados en prácticas cotidianas en el municipio de Baranoa. IE Revista de Investigación Educativa de la REDIECH, 11, e-857. doi: 10.33010/ie_rie_rediech.v11i0.857. 